\title{
Triggering Deep Convection with a Probabilistic Plume Model
}

\author{
FABIO D'ANDREA \\ Laboratoire de Meteorologie Dynamique, Paris, France \\ PierRe GENTINE \\ Columbia University, Palisades, New York \\ ALAN K. BETTS \\ Atmospheric Research, Pittsford, Vermont \\ BENJAMIN R. LINTNER \\ Rutgers, The State University of New Jersey, New Brunswick, New Jersey
}

(Manuscript received 29 October 2013, in final form 14 May 2014)

\begin{abstract}
A model unifying the representation of the planetary boundary layer and dry, shallow, and deep convection, the probabilistic plume model (PPM), is presented. Its capacity to reproduce the triggering of deep convection over land is analyzed in detail. The model accurately reproduces the timing of shallow convection and of deep convection onset over land, which is a major issue in many current general climate models.

PPM is based on a distribution of plumes with varying thermodynamic states (potential temperature and specific humidity) induced by surface-layer turbulence. Precipitation is computed by a simple ice microphysics, and with the onset of precipitation, downdrafts are initiated and lateral entrainment of environmental air into updrafts is reduced.

The most buoyant updrafts are responsible for the triggering of moist convection, causing the rapid growth of clouds and precipitation. Organization of turbulence in the subcloud layer is induced by unsaturated downdrafts, and the effect of density currents is modeled through a reduction of the lateral entrainment. The reduction of entrainment induces further development from the precipitating congestus phase to full deep cumulonimbus.

Model validation is performed by comparing cloud base, cloud-top heights, timing of precipitation, and environmental profiles against cloud-resolving models and large-eddy simulations for two test cases. These comparisons demonstrate that PPM triggers deep convection at the proper time in the diurnal cycle and produces reasonable precipitation. On the other hand, PPM underestimates cloud-top height.
\end{abstract}

\section{Introduction}

The representation of deep convection remains a key source of uncertainty, bias, and error in current generation numerical weather prediction and climate models [see, e.g., Arakawa (2004) and references therein]. Over land, a commonly encountered deficiency involves the incorrect phasing of the diurnal cycle of precipitation:

Corresponding author address: Fabio D'Andrea, Laboratoire de Meteorologie Dynamique, Ecole Normale Superieure, 24 Rue Lhomond, 75005 Paris, France.

E-mail: dandrea@Imd.ens.fr most parameterizations used in state-of-the-art general circulation models (GCMs) trigger deep convection too early, generally in phase with the peak in surface turbulent heat fluxes, whereas observed deep convection events generally occur in the late afternoon or evening (Yang and Slingo 2001; Betts and Jakob 2002; Dai and Tremberth 2004; Bechtold et al. 2004; Dai 2006). The use of large-eddy simulations (LESs), cloud-resolving models (CRMs) (e.g., Derbyshire et al. 2004; Khairoutdinov and Randall 2006; Grabowski et al. 2006; Kuang and Bretherton 2006; Couvreux et al. 2012, hereafter CA12), and observations from satellite and intensive observational campaigns (Nesbitt and Zipser 2003; Redelsperger et al. 2006; 
Nikulin et al. 2012) have recently offered new insights into the transition from shallow to deep convection, thereby stimulating improvements in the representation of this transition in GCMs, especially in the context of the deep convective diurnal cycle over land (e.g., Rio et al. 2010; Bechtold et al. 2014).

These and other studies underscore the fundamental physical processes necessary to initiate convection. Among such processes, the humidification of the free troposphere by shallow cumulus or cumulus congestus clouds has been regarded as a key element for the triggering of deep convection (Guichard et al. 2004, hereafter GA04; Chaboureau et al. 2004; Derbyshire et al. 2004; Kuang and Bretherton 2006). However, recent results suggest that congestus preconditioning is insufficient to explain the rapid transition from shallow to deep convection observed over land (Hohenegger and Stevens 2013). Planetary boundary layer processes, including turbulence and its organization by unsaturated downdrafts, density currents, and surface heterogeneities, have been shown to be key determinants in the triggering of continental deep convection (Emori 1998; Takemi and Satomura 2000; Del Genio and Wu 2010; Grandpeix and Lafore 2010; Zhang and Klein 2010, 2013; Schlemmer and Hohenegger 2014; Taylor et al. 2012).

While most GCMs have independent parameterization packages for the planetary boundary layer (PBL), shallow convection, and deep convection, the interplay of all the physical processes involved in the life cycle of convection makes a unified treatment desirable (Kuang and Bretherton 2006; Hohenegger and Bretherton 2011). Furthermore, GCMs exhibit a large sensitivity to representations of physical processes and feedbacks that involve the coupling of different parameterizations (e.g., cloud feedback) (Dufresne and Bony 2008; Sherwood et al. 2014). Over the last decade, some progress has been made toward development of unified convection schemes (Lappen and Randall 2001a,b,c; Bretherton et al. 2004; Hohenegger and Bretherton 2011; Sušelj et al. 2013). Recently, Bechtold et al. (2014) achieved improved phasing of the diurnal cycle of convection in the European Centre for Medium-Range Weather Forecasts (ECMWF) model, based on a CAPE-based closure, by changing the convective adjustment time scale and making it dependent on the coupling with the PBL. However, CAPE-based convective schemes yield cloud-base mass fluxes and precipitation rates that are tightly coupled to CAPE. Previous studies based on single-column models (SCMs) forced with observational campaign data have suggested that this predicted correlation may in fact be unrealistic (Neggers et al. 2004). Therefore, the transition between shallow and deep convection still remains a major challenge for the current generation of GCMs, especially the diurnal timing of the transition between shallow and deep convection.

In this paper, we develop an extension to a bulk model of the PBL and shallow convection based on a probability distribution function (pdf) of plumes, introduced in Gentine et al. (2013a, hereafter GA13a) and Gentine et al. (2013b, hereafter GA13b). This extension captures the initiation of deep convection; it can thus be regarded as a step toward the development of a unified convective scheme. The present paper addresses the triggering of deep convection rather than its duration or intensity for which the presence of cold pools may play a major role (Zipser 1977; Houze and Betts 1981; Johnson 1981; Johnson and Houze 1987; Qian et al. 1998; Weisman and Rotunno 2004; Grandpeix and Lafore 2010; Grandpeix et al. 2010; Zuidema et al. 2012). Indeed, cold pools are not yet explicitly considered in the current formulation of the model.

The rest of this paper is organized as follows. In section 2, the probabilistic plume model (PPM) is briefly described, while, in section 3, the modifications and improvements with respect to GA13a and GA13b are described in detail. In sections 4 and 5, the performance of the model is evaluated in two cases of deep convection. The first corresponds to a case of midlatitude summer convection for which we use forcing data obtained from observations collected over the Southern Great Plains during the summer of 1997 by the U.S. Department of Energy's (DOE) Atmospheric Radiation Measurement Program (ARM). The second represents convection over a subtropical, semiarid environment during the monsoon onset phase, with forcing obtained from data collected during the African Monsoon Multidisciplinary Analysis (AMMA) campaign during summer 2010 in West Africa. Section 6 summarizes the results and their implications.

\section{Probabilistic plume model description}

The PPM, developed by GA13a and GA13b (in which the model was referred to as the probabilistic bulk convection model) is a plume model of the PBL capable of reproducing the transition between the dry boundary layer and a shallow convection regime. A schematic of PPM is given in Fig. 1. The model is based on an ensemble of entraining updrafts generated at the surface that rise into the PBL. This ensemble of plumes is described by a pdf of three variables: their vertical speed $w$, potential temperature $\theta$, and specific humidity $q$. We assume the pdf to be a joint Gaussian distribution, defined in terms of the variances and the covariances of the three variables. 


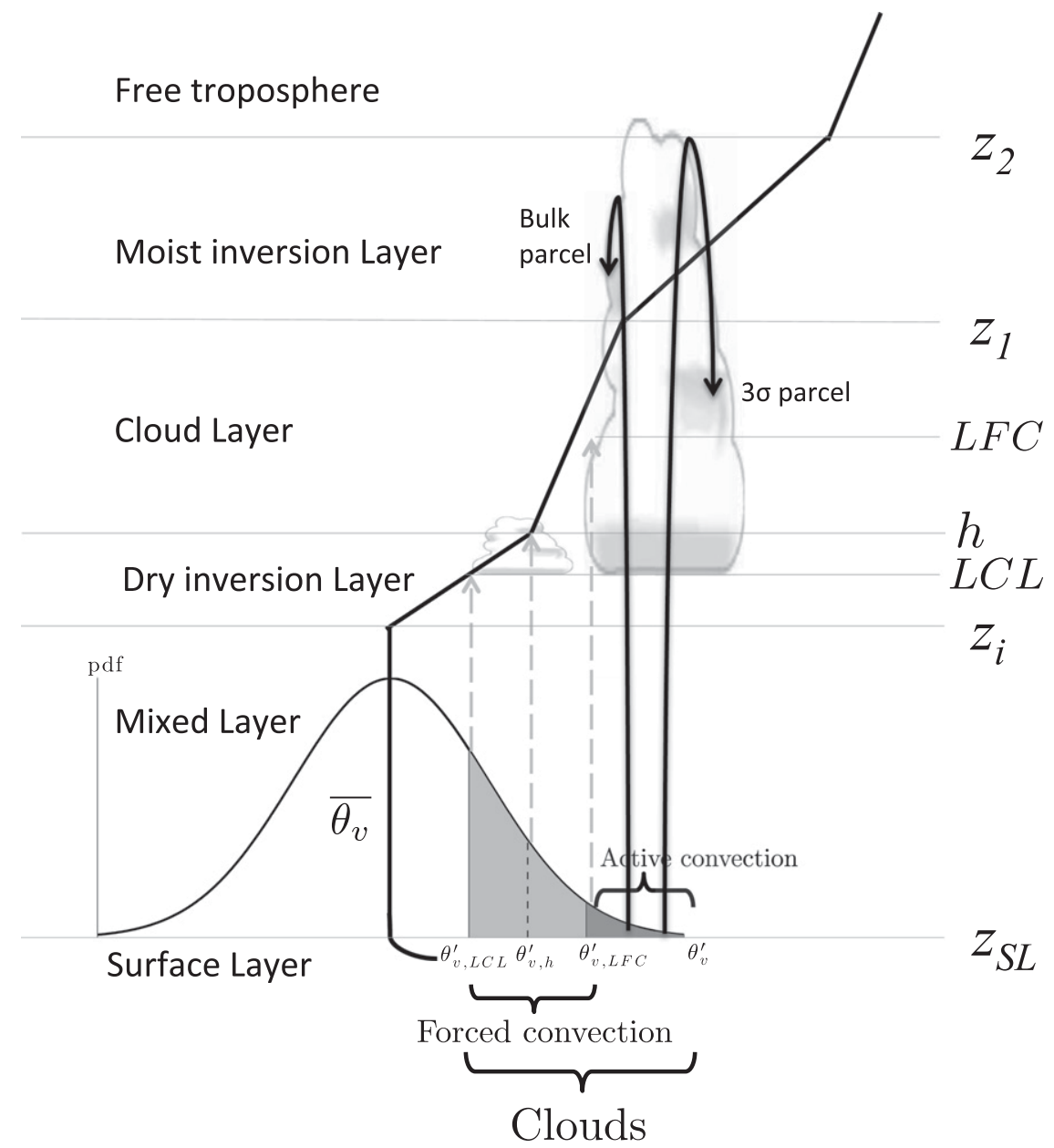

FIG. 1. Illustration of the structure of PPM. The surface distribution is depicted in terms of $\theta_{v}$ but it represents the joint pdf of vertical velocity, humidity, and potential temperature.

Surface variance scaling is obtained through a similarity with the surface sensible $\left(\overline{w^{\prime} \theta^{\prime}}\right)$ and latent $\left(\overline{w^{\prime} q^{\prime}}\right)$ heat fluxes and the convective velocity $w_{*}$ (see GA13a and GA13b for details on the construction of the surface pdfs). The additional covariance $\left(\overline{q^{\prime} \theta^{\prime}}\right)$ is assumed to be 1 . The pdf is used to compute the plumes' conserved variables (liquid potential temperature $\theta_{l}$ and total specific humidity $q_{\text {tot }}$ ) at the surface. Although it may be more appropriate to consider non-Gaussian distributions (Golaz et al. 2002; Bogenschutz et al. 2010), a simple Gaussian is in fact close to the near-surface pdf obtained by CRMs (Kuang and Bretherton 2006). Here its use is mainly motivated by analytic tractability. As described in GA13a and GA13b, the probabilistic plume approach ensures a tight coupling between the subcloud-layer entrainment velocity and the mass flux closure: the mass flux at cloud base is determined by the most buoyant plumes, originating from the surface, which are able to reach their level of free convection
(LFC), while the entrainment velocity of the subcloud layer is given by the plumes reaching the top of the interfacial layer capping the subcloud layer.

The transition between dry and shallow convection is straightforward within PPM. Forced, negatively buoyant clouds are obtained when some plumes reach their lifting condensation level (LCL) but not their LFC. Active convection, which generates a cloud-base mass flux, is defined when some plumes reach both their LCL and LFC. The plumes' distribution therefore defines both the triggering of moist convection and the mass flux closure at cloud base. Above cloud base, a two-plume model is used in lieu of the full pdf of plumes for computational efficiency (GA13a; GA13b).

A brief overview of PPM vertical structure follows here; section 3 highlights the principal modifications implemented for this study. The model is divided into six continuous layers, as illustrated in Fig. 1: 
1) The surface layer extending from the surface to height $z_{\mathrm{SL}}=0.1 z_{i}$. In this region, the temperature and humidity profiles are logarithmic following Monin-Obukhov similarity.

2) The mixed layer extending from $z_{\mathrm{SL}}$ to $z_{i}$ in which $\theta$ and $q$ are assumed to be uniform in $z$, equal to $\bar{\theta}$ and $\bar{q}$.

3) A so-called dry inversion layer between $z_{i}$ and $h$, capping the dry mixed layer. In the presence of shallow or deep convection, the LCL is generally located within this dry inversion layer and forced clouds are present.

4) The ensemble of active clouds creates a conditionally unstable cloud layer extending from LCL to $z_{1}$, where $z_{1}$ is the level of neutral buoyancy of the average updraft. The cloud layer has lapse rates $\Gamma_{\theta}^{1}$ for potential temperature and $\Gamma_{q}^{1}$ for specific humidity (between $h$ and $z_{1}$ ).

5) The most energetic cloud overshoot into the stable moist inversion layer, extending between $z_{1}$ and $z_{2}$. This layer is characterized by a lapse rate $\Gamma_{\theta}^{2}$ for potential temperature and $\Gamma_{q}^{2}$ for specific humidity.

6) The region above $z_{2}$ corresponds to the unperturbed region of the free-tropospheric profile, where the lapse rates $\gamma_{\theta}$ and $\gamma_{q}$ of potential temperature and specific humidity are specified. These lapse rates vary according to prescribed large-scale tendencies.

The model is forced by the surface heat fluxes and by the initial environmental profiles of potential temperature and specific humidity. Note that the prescribed environmental profiles do not need to be linear: they are observed profiles in their full complexity, with linearization only coming into play in the cloud layer and below. We have not yet tested PPM behavior for cases where the environmental profiles have a more complex structure, such as upper-air inversions or mixed layers.

The PPM solves a system of equations for 10 variables:

1) $\bar{\theta}, \bar{q}$, and $z_{i}$ in the dry region of the boundary layer;

2) $h$, at the top of the dry inversion layer, is the height of the PBL;

3) $\Gamma_{\theta}^{1}, \Gamma_{q}^{1}$, and $z_{1}$ in the cloud layer; and

4) $\Gamma_{\theta}^{2}, \Gamma_{q}^{2}$, and $z_{2}$ in the inversion layer.

During the day, the PBL deepens and entrains air from the environmental profiles above. At $h$, the temperature and humidity correspond to those of the initial profiles. If clouds are formed later in the day, levels $z_{1}$ and $z_{2}$ are defined, and the profiles between the two, and between $z_{1}$ and $h$, are linear with slopes $\Gamma_{\theta}^{2}, \Gamma_{q}^{2}$ and $\Gamma_{\theta}^{1}$, $\Gamma_{q}^{1}$, respectively. Above $z_{2}$, the environmental profiles are not modified, except by the large-scale tendencies of moisture and temperature that are added as external forcing.
The entrainment velocity at the top of the mixed layer is computed as a function of the average turbulent kinetic energy of the updrafts, subject to the condition that the parcels be sufficiently energetic to overshoot the capping inversion zone (see the detailed discussion in GA13a and GA13b). In other words, updraft surface buoyancy must exceed a threshold value $\theta_{v, h^{\prime}}$ (see Fig. 1) that is determined by the environmental vertical profiles. Since the pdf of the parcel is prescribed and related to the surface heat fluxes, the conditional probability can be computed. By a similar argument, we can obtain the cloud-base mass flux from the average velocity-at the LCL —of the active updrafts (i.e., those that have also reached their LFC). Hence, the active updrafts are those that have a surface virtual temperature above a threshold $\theta_{v, \text { LFC }}$. The vertical entrainment at the top of the subcloud layer and cloud-base mass flux are consequently constrained by the surface pdf. In this way, there is consistency between the cloud-base mass flux and the subcloud layer growth, unlike previous approaches imposing independent parameterizations.

When clouds are present, the cloud and moist inversion layers are described using a two-updrafts approach and a classical entraining plume model as in Siebesma et al. (2003). The average active parcel (i.e., the mean updraft properties averaged across all parcels reaching their LFC) is used to find $z_{1}$ and its rate of growth, while $z_{2}$ is found as the highest altitude attained by the most energetic updraft, defined as an updraft having a virtual potential temperature anomaly equal to 3 times the standard deviation of the pdf of the convectively active parcels. See Fig. 1 for an illustration. The mass flux profile in the cloud is determined by an entrainment-detrainment parameterization following De Rooy and Siebesma (2010). The detrainment rate is such that the mass flux decreases exponentially in the cloud layer and linearly to 0 in the inversion layer. This formulation implies that the most energetic parcels will reach higher altitudes, which is somewhat in contradiction with recent papers by Romps (2010) or Böing et al. (2012), showing that the inherently stochastic nature of the entrainment process would make the parcel forget its initial buoyancy. We chose to retain the simple entraining-plume formulation principally for analytic tractability, but a natural extension of the model would involve implementing a stochastic entrainment coefficient.

In GA13a and GA13b, PPM was tested against LES integrations of several standard cases of clear-sky and shallow convection conditions. In all cases, PPM accurately reproduced the PBL height, timing of initiation of convection, cloud fraction, cloud-base mass flux, and the vertical profiles of temperature and moisture. 


\section{Extension to deep convection}

Four main modifications have been introduced to simulate the transition to deep convection: 1) the introduction of ice physics in the moist adiabats, 2) addition of a minimal cloud microphysics and precipitation parameterization, 3) implementation of lateral entrainment dependence on deep convective onset, and 4) addition of parameterized precipitating downdrafts. As discussed in more detail below, the onset of deep convection is not imposed as an a priori switch between different states; rather, deep convection is defined implicitly as when precipitation reaches the surface. When this occurs, a scaling of the cloud lateral entrainment is introduced corresponding to the changes in the geometry of the updrafts due to the organization of turbulence in the subcloud layer. We note that these modifications do not affect the simulation of the clear sky and shallow convection cases presented in GA13a and GA13b.

\section{a. Ice physics in moist adiabats}

In the cloud layer, trajectories of the bulk updrafts are determined by an entraining-plume model (Siebesma et al. 2003), in which the path of the updrafts differs from the moist adiabatic because of the entrainment of environmental air. The ice moist adiabat is computed numerically by imposing conservation of the ice-liquid water potential temperature $\theta_{i l}$ [as defined in Bryan and Fritsch (2004)]. The ice-liquid fraction is parameterized as a function of temperature, ranging from all ice at $-40^{\circ} \mathrm{C}$ to all liquid at $0^{\circ} \mathrm{C}$. In lieu of a linear ice fraction, a hyperbolic tangent function is fitted between these two limits to avoid derivative discontinuity, which leads to numerical issues when computing the adiabatic profile through iteration.

\section{b. Precipitation}

This ice moist adiabat computation gives the amount of liquid and solid water in the updraft as a function of height. The associated mass flux is found using the analytical entrainment-detrainment scheme of De Rooy et al. (2013). There is no equation for the time evolution of ice and liquid water; rather, they are obtained diagnostically at every time step. The precipitation flux is found following Hohenegger and Bretherton (2011) and Boville et al. (2006) for the autoconversion threshold and the reevaporation of precipitation and using the formulation of Emanuel (1991) for the precipitation efficiency. All condensate above a threshold of $l_{p}=$ $1 \mathrm{~g} \mathrm{~kg}^{-1}$ is transformed into embryonic raindrops. Of this, only a part is transformed into precipitation, based on an efficiency coefficient varying linearly with cloud depth expressed in pressure. The efficiency is 0 below a minimum depth of $\Delta p_{\min }=150 \mathrm{hPa}$ and reaches 0.99 above $\Delta p_{\max }=650 \mathrm{hPa}$. The details of the precipitation scheme are given in appendix A. Sensitivity to the selected values of $l_{c}$ and $\Delta p_{\min }$ is assessed in sections $4 \mathrm{~b}$ and $5 \mathrm{~b}$ below.

\section{c. Lateral entrainment}

As mentioned, we define the transition to deep convection to occur when precipitation reaches the surface. When this occurs, a scaling of the cloud lateral entrainment is introduced. Precisely how environmental air mixes into convective plumes remains an area of intense research interest [see the recent review of De Rooy et al. (2013)]. The sensitivity of parameterized convection to lateral entrainment has been demonstrated across a hierarchy of models ranging from theoretical prototypes to full-fledged GCMs (e.g., Murphy et al. 2011; Holloway and Neelin 2009; Sahany et al. 2012; Lintner et al. 2012). There is evidence that entrainment is much weaker for deep than shallow convection (Del Genio and Wu 2010), to the point that the definition of deep (as opposed to shallow) convection can hardly be separated from the definition of entrainment. There is no consensus on what physical process controls the magnitude of entrainment in the transition from shallow to deep convection, with different processes leading to distinct parameterizations (Willett et al. 2008; Gregory 2001; Neggers et al. 2009). Several studies (Del Genio and Wu 2010; Kuang and Bretherton 2006; Khairoutdinov and Randall 2006; Mapes and Neale 2011) support the idea that penetrating unsaturated downdrafts bring cold, denser air into the PBL. Cold pools induced by unsaturated downdrafts modify and organize the PBL turbulence, creating larger eddies (Tompkins 2001) that lower the lateral entrainment of subsequent updrafts. This decrease of entrainment rate with increasing eddy size can be understood in terms of geometrical arguments based on classical plume theory (Simpson and Wiggert 1969). Consider a cylindrical plume: the ratio of the plume boundary surface to the plume volume decreases with plume radius $r$ as $1 / r$. Since lateral entrainment of environmental air takes place at the boundary of the plume while the plume mass flux scales with area, entrainment should scale as $1 / r$.

The entrainment is represented in PPM by a classical linear mixing with a coefficient $\epsilon$. We use the expression for $\epsilon$ proposed by Siebesma et al. (2007): $\epsilon=c_{\epsilon} / z$, where $c_{\epsilon}$ is an adjustable parameter that they set equal to 1 . In GA13a, $c_{\epsilon}$ is also set to 1 and held constant. Here, we use the geometrical argument described above and assume an aspect ratio of order unity for the plumes. Hence, 
with the onset of deep convection, lateral entrainment is rescaled so that the largest eddies correspond to the entire circulation extending up to the cloud top. The new lateral entrainment then becomes

$$
\epsilon=\frac{c}{z}=c_{\epsilon} \frac{z_{i}}{z_{2}} \frac{1}{z},
$$

where $z_{i}$ is the depth of the mixed layer and $z_{2}$ is the top of the clouds as defined above. This is up to one order of magnitude smaller than the shallow convection lateral entrainment rate. We apply this scaling only when precipitation is generated and reaches the ground without evaporating (i.e., our diagnostic for the onset of deep convection). In the absence of precipitation, as under shallow convection, a typical eddy size scales with $z_{i}$, so scaling by $z_{i}$ in (1) gives $c=c_{\epsilon}$ and we recover the original GA13a formulation. A reduction of the entrainment rate according to cloud height is also found by Stirling and Stratton (2012), who employed a scaling similar to (1) for deep convection, and by Hohenegger and Bretherton (2011), although in their case the dependence is on precipitation rate rather than cloud height. In our case, the geometrical considerations above make cloud height a more natural choice.

The value of $c_{\epsilon}$ remains an ad hoc parameter. Values of $c_{\epsilon}$ reported in the literature range from as low as 0.4 to as high as 1 (e.g., De Rooy et al. 2013). In our case, a sensitivity study to changes of $\pm 20 \%$ advances or delays the triggering of convection by around $30 \mathrm{~min}$, with clouds top lowered or elevated by about $400 \mathrm{~m}$. The exact figures of the sensitivity study are presented below in sections $4 \mathrm{~b}$ and $5 \mathrm{~b}$ (see Tables 1 and 2 , respectively).

\section{d. Downdraft humidity and temperature}

Betts (1976) and more recently Hohenegger and Bretherton (2011) (cf. their Fig. 3) showed how downdraft moist static energy (MSE) and equivalent potential temperature $\theta_{e}$ follow the environmental value down to a level near or slightly above the LCL and then remain almost constant below cloud base. Rain evaporation increases with downdraft velocity, environmental dryness, and decreasing rain droplet size, and the temperature of the downdraft tends toward the wet-bulb temperature with sufficient fallout velocity. In general, the downdraft air also maintains a constant saturation equivalent potential temperature $\theta_{e \text {,sat }}$ (Betts and Silva Dias 1979).

Hence, we compute $\theta_{e}$ and $\theta_{e \text {,sat }}$ and the moist static energy $s_{e}$ at the LCL and use their conservation to estimate a temperature and a humidity for the downdraft at the top of the subcloud layer (suffix "top" in the equations below) and at the surface (suffix "sfc"); between the two, we will assume a linear profile for simplicity. At the
LCL, the potential temperature of the downdraft $\theta_{d}^{\text {top }}$ is the wet-bulb temperature given the environmental temperature and humidity, multiplied by the Exner function at the pressure of the LCL. The humidity of the downdraft $q_{d}^{\text {top }}$ follows from conservation of $s_{e}$ at the LCL:

$$
q_{d}^{\mathrm{top}}=\frac{1}{L_{e}}\left(s_{e}-c_{p} \theta_{d}^{\mathrm{top}}\right)
$$

The temperature and humidity of the downdraft at the surface, $\theta_{d}^{\text {sfc }}$ and $q_{d}^{\text {sfc }}$, are computed by solving the following system of equations expressing the conservation of $\theta_{e}$ and $\theta_{e, \text { sat }}$ :

$$
\left\{\begin{array}{l}
\theta_{e}=\theta_{d}^{\mathrm{sfc}}+\left(\frac{L_{e}}{c_{p}} q_{d}^{\mathrm{sfc}}\right) \\
\theta_{e, \mathrm{sat}}=\theta_{d}^{\mathrm{sfc}}+\frac{L_{e}}{c_{p}} q_{\mathrm{sat}}\left(T_{d}^{\mathrm{sfc}}, p_{s}\right)
\end{array}\right.
$$

indicating by $q_{\mathrm{sat}}(T, p)$ the saturation specific humidity given by the Clausius-Clapeyron law for a given temperature and pressure.

The mass flux of the downdraft is estimated as $M_{d}=$ $\alpha M_{u}$, with $\alpha=0.2$ following Emanuel (1991) [see also Tiedtke (1989) and references therein]. The difference of humidity between the environment and the downdraft is obtained by evaporating the precipitation, so that the precipitation flux is reduced by $\delta P=M_{d}\left[q_{d}-q_{\mathrm{env}}(\mathrm{LCL})\right]$. The balance of temperature and humidity in the PBL due to the penetrating downdrafts is detailed in appendix B.

The triggering time for deep convection is not sensitive to the value of the coefficient $\alpha$. However, the evolution of the clouds and of the PBL after the triggering is sensitive to $\alpha$, as described in the sensitivity analysis in sections $4 \mathrm{~b}$ and $5 \mathrm{~b}$ below.

\section{Summer midlatitude case}

In this section we show the behavior of PPM for midlatitude continental summertime convection, based on observations from the DOE ARM Southern Great Plains site in Oklahoma for 27 June 1997, conducted in the framework of the European Cloud Systems (EUROCS) project (Siebesma et al. 2004). These data were used to produce a set of forcings used as a standard test case in different programs like Global Energy and Water Exchanges (GEWEX). The PPM was run using this set of forcings.

GA04 conducted an extensive comparison of singlecolumn models and CRMs using this case. The evolution of the meteorological situation of the day is thoroughly 

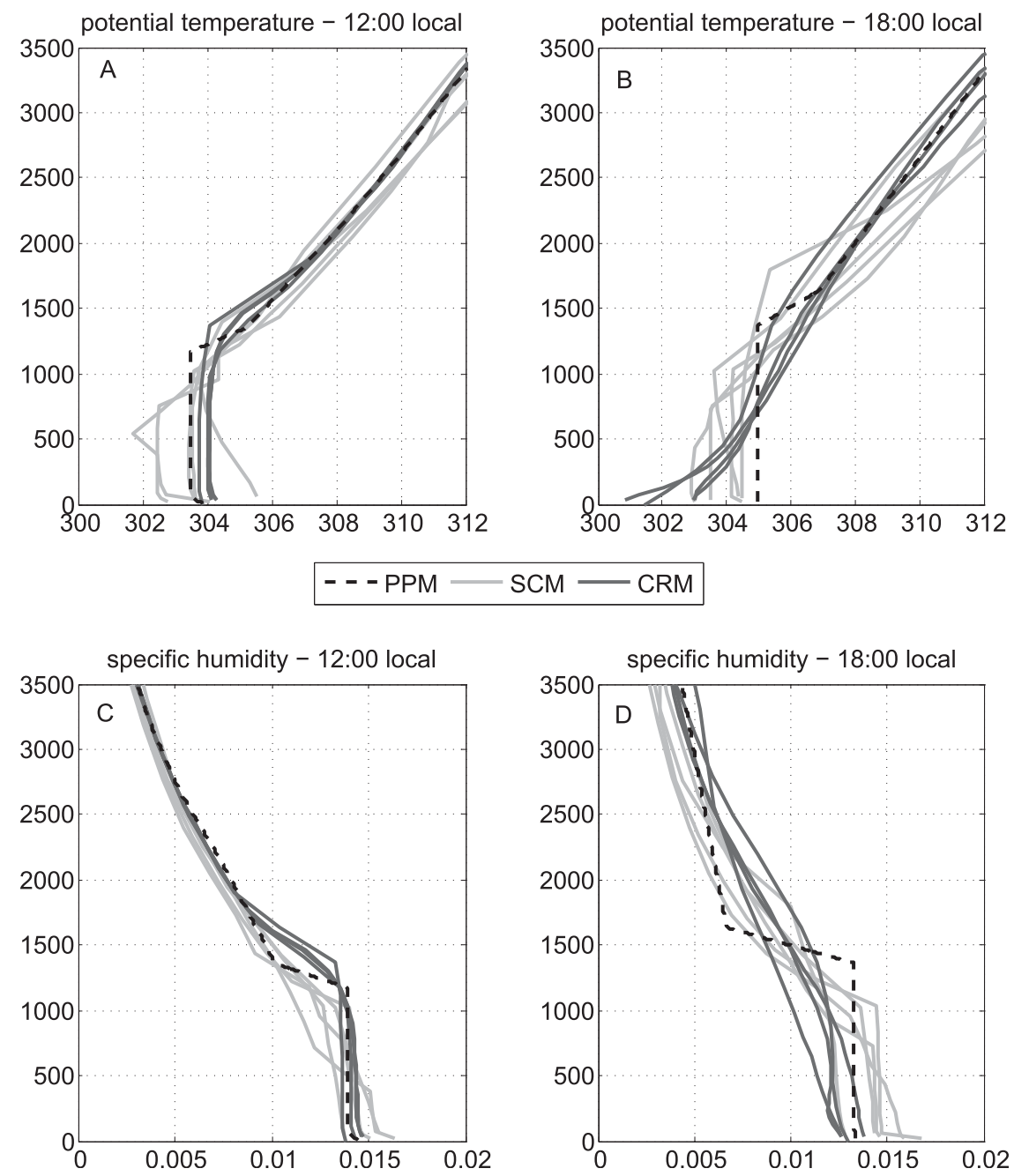

FIG. 2. (top) Potential temperature profiles (K) at (a) 1200 and (b) 1800 LT. (bottom) Specific humidity profiles $\left(\mathrm{g} \mathrm{kg}^{-1}\right)$ at (c) 1200 and (d) 1800 LT. In all panels, PPM is the black dashed line, CRMs are the dark gray lines, and SCMs are the light gray lines.

described in GA04. In summary, low clouds first appeared around 1000 local time (LT; 1500 UTC), and a sudden triggering of a deep cumulus occurred around local noon, along with precipitation. GA04 documented considerable spread in the performance of the CRMs and SCMs in simulating the diurnal cycle of convection in this case study. In particular, SCMs typically triggered deep convection 3-6 h too early, with some SCMs failing to trigger at all, and yielded a large range in simulated cloud heights. Indeed, some SCMs produced very unphysical behavior with convection repeatedly switching on and off (see, e.g., their Fig. 13). Overall, CRMs performed better with respect to phasing of the diurnal cycle, with rainfall commencing between 1200 and 1230 LT and maximizing later during local afternoon, but still with relatively large spreads in precipitation and cloud height.

\section{a. PPM integration}

The PPM is initialized with the early morning profiles of this day and forced by large-scale convergence of moisture and temperature, as well as by surface fluxes. It is integrated from $0530 \mathrm{LT}$ and interrupted at $1800 \mathrm{LT}$. The model is stopped in the late afternoon since it does not treat the nighttime stable boundary layer. Moreover, as will become clearer below, some of the processes that may contribute to maintaining deep convection after triggering are not yet included in the model.

Figure 2 depicts the potential temperature and specific humidity profiles of PPM compared to the CRMs and SCMs of GA04. This figure is similar to Figs. 5 and 6 in GA04; the profiles are shown at 1200 LT, just before the triggering of deep convection, and at $1800 \mathrm{LT}$. The PPM is seen to lie largely within the range of variability of the 


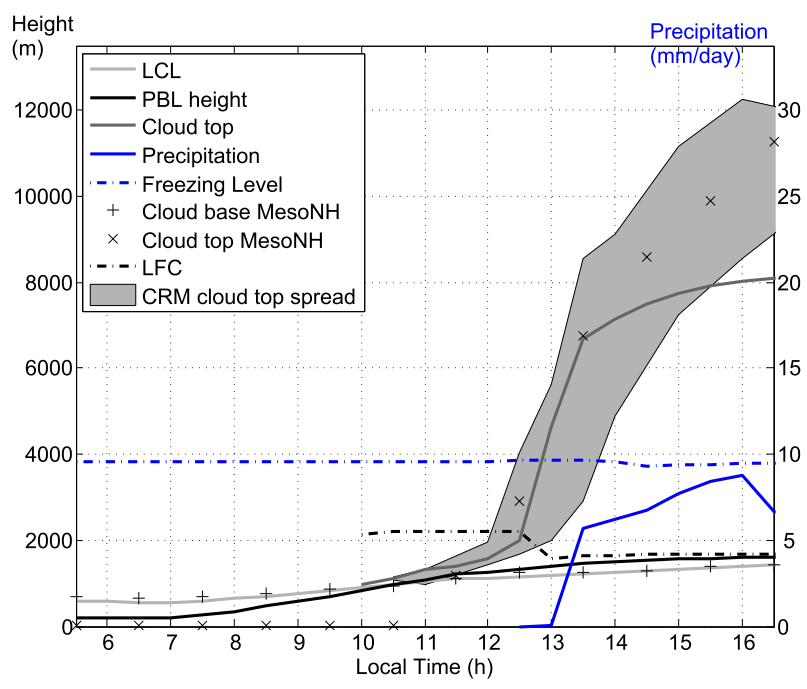

FIG. 3. Time evolution of the PBL height (black), LCL (light gray), top of the clouds (dark gray), and precipitation (blue). The gray shading represents the spread of the top of the cloud height of the CRM participating in the comparison of Guichard et al. (2004). MesoNH cloud-top height $(\times)$ and LCL $(+)$ are also shown.

models included in GA04. Limiting the comparison to the CRMs, it appears that PPM is slightly colder than the average CRM in the lower layers at noon. This can be explained either by a too-shallow PBL or by the fact that the radiative effect of morning low clouds is not considered in PPM. The latter is particularly plausible given the fact that PPM performs very well in clear-sky conditions against LES data (see GA13b). The depth of the dry inversion layer $\left(h-z_{i}\right)$ is less than in the CRMs. As currently computed in PPM, $h$ uses the parameterization of Neggers et al. (2009), which may be insufficiently accurate. On the other hand, the CRM resolution is insufficient to resolve the dry inversion layer: as Sullivan and Patton (2011) have recently shown, CRMs or LES with coarse vertical resolution overestimate the depth of the inversion layer, often by a factor of 2 . At 1800 LT, PPM has a higher PBL than most SCMs and is moister and warmer in the lower layers; the difference with respect to the CRMs is smaller. The excess lowlevel heating and moistening in PPM likely arises from underestimation of drying and cooling from unsaturated downdrafts and is in fact consistent with the underestimation of cloud heights and mass fluxes as discussed below.

In Fig. 3, we show the diurnal evolution of the vertical level structure of PPM compared to CRMs. The continuous lines are the PPM outputs. The dark gray line denotes the PPM cloud top; it can be compared with the gray shaded area representing the spread of cloud-top heights as estimated from the four CRMs depicted in

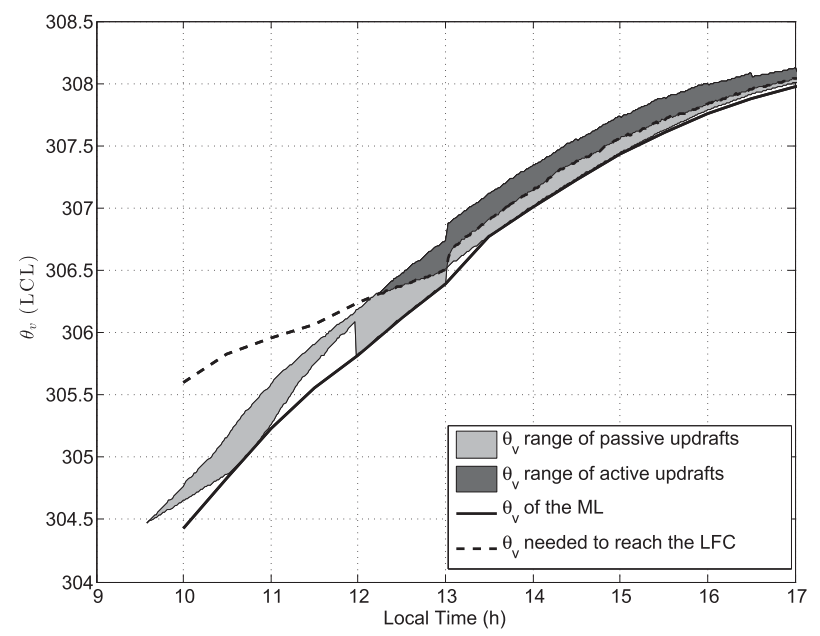

FIG. 4. Time evolution of the mixed-layer virtual potential temperature at the LCL (black solid line). Range of the virtual potential temperatures at the LCL for all the updrafts that have reached the LCL at a given time (gray shaded area): active updrafts are dark gray and passive updrafts are light gray. Black dashed line is the minimum $\theta_{v}$ at the LCL needed to reach the LFC.

Fig. 13a in GA04. For reference, the LCL and cloud-top height from one of these models, the Modele Mesoeschelle Nonhydrostatique (MesoNH; Lafore et al. 1998), at 2-km resolution are also shown (crosses). Note that it is not our intention here to reproduce the output of this particular CRM, given the range of behavior simulated by the ensemble of CRMs analyzed in GA04. Rather, we show these data as benchmarks for the appearance of clouds, the triggering of deep convection, and cloud heights in a representative CRM. The PPM generates clouds at 0945 LT these clouds remain low until $1200 \mathrm{LT}$, corresponding to a cumulus humilis phase. In this period, the most energetic updrafts do not reach the LFC and the clouds remain forced (Stull 1985; Wilde et al. 1985; Zhang and Klein 2010). Around 1230 LT, the updrafts attain the LFC and a deep cloud forms and rapidly thereafter reaches its freezing level, with precipitation simultaneously commencing. Subsequently, the cloud continues to grow until it reaches a maximum height of slightly above $8 \mathrm{~km}$, or roughly $2-4 \mathrm{~km}$ below the cloud tops simulated by the CRMs. The peak precipitation, around $9.5 \mathrm{~mm} \mathrm{day}^{-1}$, occurs around 1600 LT, comparable in timing and amplitude to the CRMs in GA04. We deliberately exclude from this comparison the SCMs analyzed by GA04, given their clearly unphysical behavior described above. Overall, these results indicate PPMs capacity to simulate the temporal progression from clear sky to cumulus humilis, followed by cumulus congestus and deep convection phases, which is a major challenge for current generation SCMs. 

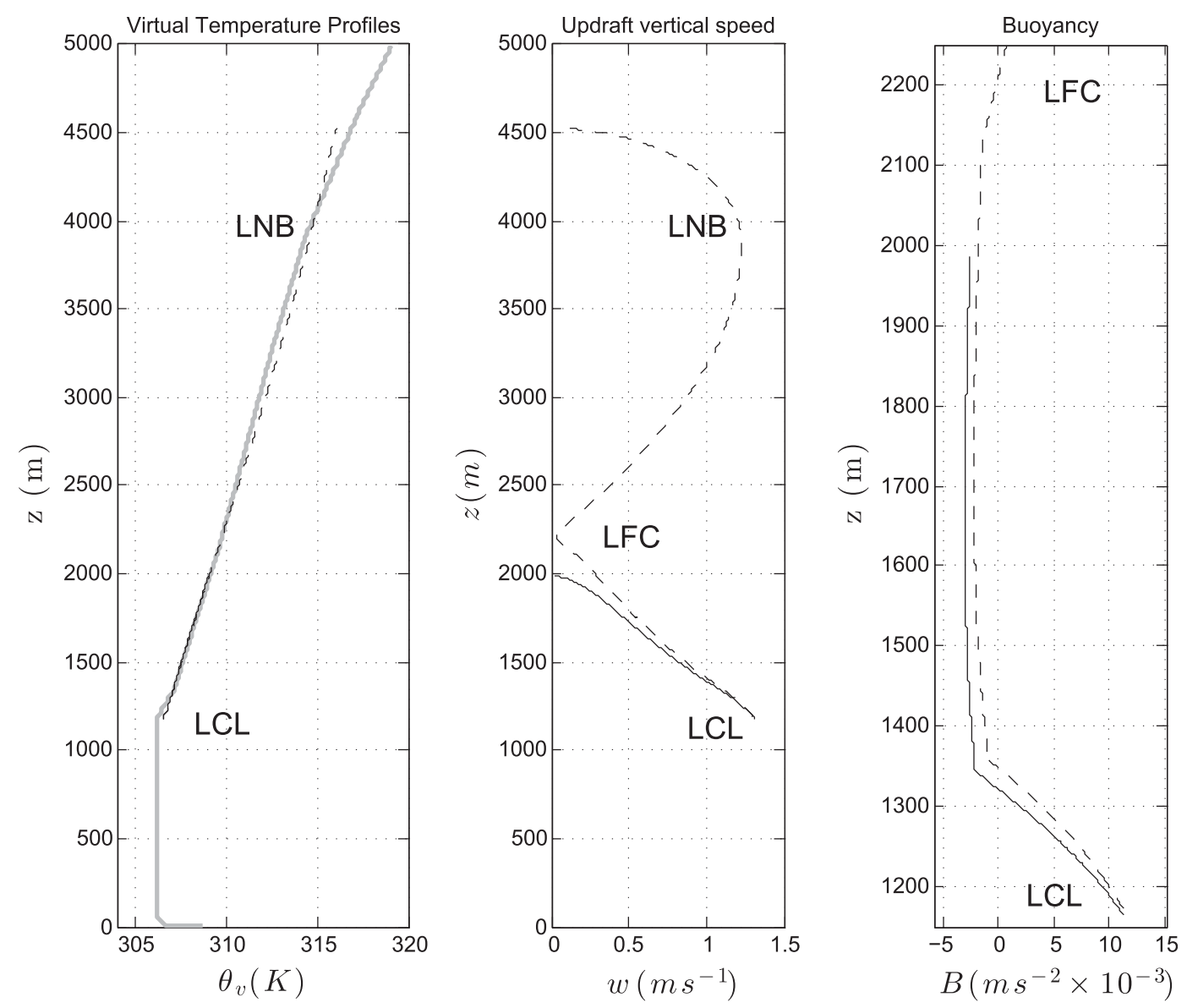

Environment - - -12:35 updraft $-11: 30$ updraft

FIG. 5. Trajectory of two updrafts, immediately before (1200 LT) and immediately after (1235 LT) reaching the LFC. (a) The virtual potential temperature of the environment (gray) and the virtual potential temperature of the updraft parcels along its trajectory (black), (b) the vertical speed of the parcels, and (c) the buoyancy profile of the particles, zoomed in on the vertical region around the LFC.

Figure 4 shows the evolution of the system in terms of virtual potential temperature at the LCL. Here, the $\theta_{v}$ of the mixed layer is shown in solid black; the gray shaded area represents the range of the updrafts $\theta_{v}$ that have reached the LCL i.e., those for which $\theta_{v}$ is higher than $\theta_{v, \mathrm{LCL}}$ at a given time (see Fig. 1). The dashed line represents the virtual potential temperature that a parcel needs to have at the LCL in order to reach the LFC. It can be seen that the first updrafts overshoot their LCL before $1000 \mathrm{LT}$, leading to the formation of forced clouds. Active convection ensues at the time when the most buoyant updraft, corresponding to the upper limit of the gray area in Fig. 4 , has $\theta_{v}=\theta_{v \text {, LFC }}^{\prime}$, around $1230 \mathrm{LT}$ (i.e., the black dashed line enters the shaded area). Later in the day, more and more of the updrafts reaching the LCL are active; their range of $\theta_{v}$ is given in the dark part of the gray shading.
The behavior of the first parcels reaching the LFC is illustrated in Fig. 5. In Fig. 5a the profiles of virtual potential temperature of the most energetic updraft at 1235 LT (dashed) and of the environment (gray) are plotted; the profiles of an updraft initiated $5 \mathrm{~min}$ before are also plotted for comparison (solid line; note that in Fig. 5a it is barely distinguishable from the other two). Above the LFC, the environmental profile is very close to the moist adiabatic profile of the updraft, and the effect of entrainment and mixing of the $1235 \mathrm{LT}$ parcels with environmental air is small since the parcels have a buoyancy very close to that of the environment. The effect is that the level of neutral buoyancy (LNB) is very high, and parcels remain buoyant for a long stretch. The 1235 LT updraft originates at the LCL, which lies in the dry inversion zone between $z_{i}$ and $h$. The parcel is initially buoyant, but as soon as it exits the PBL, above $h$, it 
becomes negatively buoyant. However, its kinetic energy is sufficiently high to allow it to reach the LFC, which is located at around $2200 \mathrm{~m}$. This is clear from Fig. $5 \mathrm{~b}$ where the vertical velocity of the parcel is shown (dashed line); the speed decreases but remains positive up to the LFC and then starts increasing again. The parcel remains buoyant until around $4000 \mathrm{~m}$ and then overshoots for another $500 \mathrm{~m}$ before reaching its maximum altitude. At that moment, precipitation starts and the entrainment is further reduced. The parcels initiated subsequently experience a smaller entrainment rate and reach higher altitudes, so that by 1300 LT the cloud top extends above $6000 \mathrm{~m}$. The vertical velocity of the 1230 LT parcel is also shown in Fig. $5 b$ (solid line). In this case, the parcel does not reach the LFC, as its vertical speed goes to zero just below it, and thus the parcel reaches a highest altitude of around $2000 \mathrm{~m}$. The contrasting behavior of the two updrafts is better illustrated in Fig. 5c, which highlights the buoyancy profile in the region between the LCL and LFC: while both parcels are negatively buoyant above the dry inversion, the slight increase of buoyancy at the base of the clouds is sufficient to allow the 1235 LT parcel (dashed line) to reach the LFC, where the buoyancy becomes positive once again.

The reduction of the entrainment rate is responsible for the growth of the cloud after the initial triggering. This is illustrated by performing an integration of PPM in which the scaling of the entrainment rate described in section 3 is removed; that is, the entrainment rate is kept constant as in GA13a (Fig. 6). It can be seen that convection is triggered at the same time as in Fig. 3, and while trace rainfall initially occurs, after $30 \mathrm{~min}$ the cloud top is lower; subsequently, the cloud experiences little growth and precipitation remains very weak. In other words, a cumulus congestus is created, and precipitation initiated, but it does not evolve into a deep cumulus. Note that for this case, the congestus phase does not have time to moisten the environment and thus it does not appear essential for the triggering of deep convection, which is consistent with the results of (Hohenegger and Stevens 2013).

In PPM, the triggering of convection is determined by the interplay between (i) the distribution of the thermodynamic properties of the plumes at the surface; (ii) the thermodynamic properties of the mixed layer and most importantly the strength of the dry inversion, which regulates the cloud-base mass flux (GA13a); and (iii) the depth of the mixed layer that controls the convective velocity through the surface buoyancy flux. These factors, in addition to a conditionally unstable profile in the free troposphere, cause the rapid deepening of the clouds and the onset of precipitation. By contrast, the reduction of entrainment is not the initial

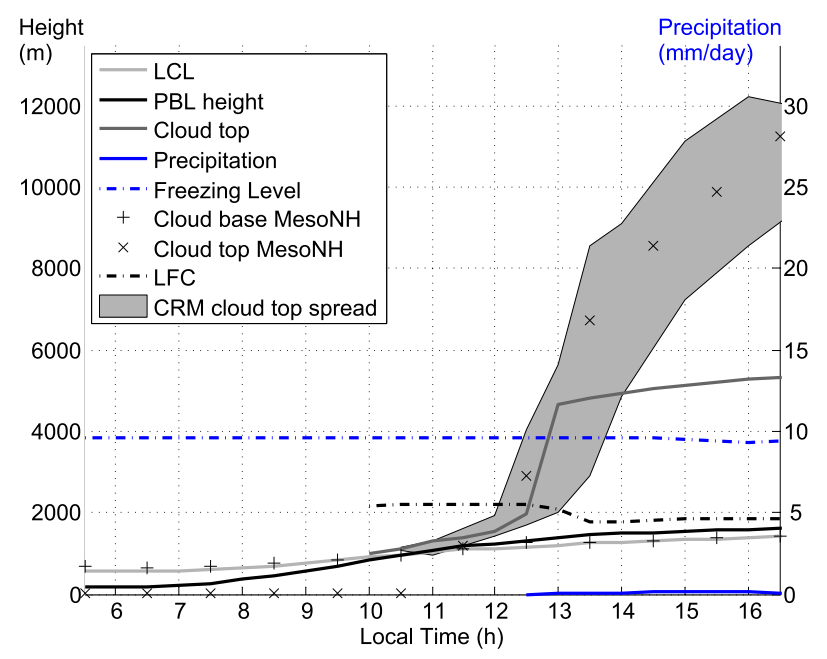

FIG. 6. As in Fig. 3, except using constant entrainment rate.

cause of the triggering, as it intervenes only after the appearance of rain. However, it is responsible for the maintenance and the deepening of the convective cloud and for the transition from the precipitating congestus phase to the deep cumulonimbus phase.

In section 3, we suggest that the decrease of the updraft lateral entrainment may be related to unsaturated downdrafts penetrating the PBL and organizing the turbulence through cold pools. The expansion of cold pools, however, has other important effects-namely, the mechanical lifting of updrafts via the expansion of density currents (Grandpeix and Lafore 2010; Grandpeix et al. 2010; Schlemmer and Hohenegger 2014), especially where they collide. Cold pools may further impact the shape of the pdfs of boundary layer turbulence, which determine the thermodynamic properties of the updrafts (Tompkins 2001). These effects are not included in the current version of PPM, and they may account for why the cloud height is currently underestimated, since the additional moist static energy generated by such processes would favor higher clouds.

\section{b. Sensitivity study}

A sensitivity study of the performance of PPM to changes in a few key parameters-including the lateral entrainment coefficient, ratio of downdraft mass flux to updraft mass flux, autoconversion threshold, minimum cloud height for precipitation occurrence, and evaporative fraction-has been conducted and is summarized in Table 1. The impact of changing these parameters is assessed in terms of four indicators: the time of triggering of low and deep clouds, the maximum cloud-top height, and the total accumulated rainfall. The first two are particularly pertinent given our emphasis on the 
TABLE 1. Summary of the sensitivity integrations: summer midlatitude case.

\begin{tabular}{|c|c|c|c|c|c|}
\hline Brief description of integration & $\begin{array}{l}\text { Parameter } \\
\text { values }\end{array}$ & $\begin{array}{l}\text { Low cloud } \\
\text { time (LT) }\end{array}$ & $\begin{array}{l}\text { Deep cloud } \\
\text { time (LT) }\end{array}$ & $\begin{array}{l}\text { Max cloud } \\
\text { height }(\mathrm{m})\end{array}$ & $\begin{array}{l}\text { Accumulated rainfall } \\
\qquad\left(\mathrm{kg} \mathrm{m}^{-2}\right)\end{array}$ \\
\hline Reference & & 0945 & 1235 & 8124 & 1.37 \\
\hline \multirow[t]{2}{*}{ Lateral entrainment; reference $=1.0$} & $c_{\epsilon}=0.8$ & 0945 & 1205 & 8536 & 1.75 \\
\hline & $c_{\epsilon}=1.2$ & 0945 & 1315 & 7604 & 0.91 \\
\hline \multirow{2}{*}{ Downdraft mass flux; reference $=0.2$} & $\alpha=0.5$ & 0945 & 1235 & 7767 & 0.71 \\
\hline & $\alpha=0.8$ & 0945 & 1235 & 7562 & 0.42 \\
\hline \multirow{2}{*}{$\begin{array}{l}\text { Autoconversion threshold; } \\
\text { reference }=1\left(\mathrm{~g} \mathrm{~kg}^{-1}\right)\end{array}$} & $l_{p}=0.5$ & 0945 & 1235 & 7663 & 1.19 \\
\hline & $l_{p}=2$ & 0945 & 1235 & 8714 & 1.43 \\
\hline $\begin{array}{l}\text { Min cloud height for precipitation; } \\
\text { reference }=150(\mathrm{hPa})\end{array}$ & $\Delta p_{\min }=50$ & 0945 & 1235 & 7309 & 1.51 \\
\hline \multirow{3}{*}{$\begin{array}{l}\text { Evaporative fraction; reference }= \\
0.75-0.8 \text { (Percentage of reference) }\end{array}$} & $105 \%$ & 0950 & 1235 & 8185 & 1.48 \\
\hline & $75 \%$ & 0925 & 1155 & 7800 & 0.82 \\
\hline & $50 \%$ & 0915 & 1120 & 7418 & 0.38 \\
\hline
\end{tabular}

triggering of deep convection. We include the last two as they build physical intuition, as will become clear below.

We first assess the sensitivity to changes in $c_{\epsilon}$, the lateral entrainment parameter of Siebesma et al. (2007). In the reference case, this parameter is equal to 1 ; here we consider variations of $\pm 20 \%$. Decreasing $c_{\epsilon}$ results in updrafts reaching a higher altitude for the same initial buoyancy. Consequently, deep convection triggering occurs $30 \mathrm{~min}$ earlier than in the reference case, with a cloud top $400 \mathrm{~m}$ higher and increased precipitation rate. Increasing $c_{\epsilon}$ has the opposite effect, with a delay of deep convection triggering of about $40 \mathrm{~min}$, and a corresponding reduction of cloud height and rain.

Parameter $\alpha$ is the ratio of downdraft mass flux to updraft mass flux of Emanuel (1991); it is set to 0.2 in the reference and is here tested for higher values, following the suggestion of, for example, $\mathrm{Xu}$ and Randall (2001) that this ratio could be as high as 0.6. While increasing the downdraft mass flux ratio does not obviously influence the triggering of either low or deep convective clouds, once deep convection and rain are initiated a higher downdraft mass flux reduces the moist static energy in the PBL and hence reduces cloud top and rainfall. In fact, the thermodynamics of PBL is very sensitive to this parameter, as increasing mass flux increases PBL height, and the temperature is reduced by as high as $2 \mathrm{~K}$ for $\alpha=0.8$ (not shown).

Given the importance of precipitation in our definition of deep convection, two parameters of the very simple microphysics scheme of PPM are tested here. The terms $l_{p}$ and $\Delta p_{\min }$ are, respectively, the autoconversion threshold and the minimum cloud depth for precipitation, set to $1 \mathrm{~g} \mathrm{~kg}^{-1}$ and to $150 \mathrm{hPa}$ in the reference. Changing either $l_{p}$ or $\Delta p_{\text {min }}$ does not influence the hour of cloud triggering. Not surprisingly, both parameters have an impact on the amount of rainfall. Reducing $\Delta p_{\min }$ obviously increases the amount of rain.
On the other hand, the results for $l_{p}$ are less intuitive. Increasing $l_{p}$ reduces the number concentration of raindrops, so that one would expect a reduction of rainfall, but an increase is observed instead. Conversely, reducing the autoconversion threshold reduces rainfall. In fact, increasing the threshold does initially reduce rainfall (not shown), but at the same time the increased water available for detrainment humidifies the environment, so that subsequent updrafts are less affected by entrainment and reach higher levels. Higher clouds are more efficient in producing precipitation, so that the net effect enhances rainfall. The opposite is observed if the threshold is reduced.

The sensitivity to changing evaporative fraction is less of a model parameter sensitivity test and more of an assessment of the physical mechanisms coupling the surface and convection. The model is driven by the surface sensible $(H)$ and latent $(\lambda E)$ heat fluxes. The evaporative fraction, defined as $\mathrm{EF}=\lambda E /(H+\lambda E)$ is high in this case study (0.75-0.8): in fact, values of EF higher than 0.8 are quite unusual even in the wet season in the tropics [see Mercado et al. (2009) and references therein]. Typically EF is roughly constant during the day (Crago 1996b,a; Gentine et al. 2007, 2011). We explored the sensitivity to percentage variation in EF while keeping the available energy $(H+\lambda E)$ constant. This represents a hypothetical moistening or drying of the soil. Table 1 shows that the triggering of shallow and deep cloud is up to $90 \mathrm{~min}$ for a $50 \%$ reduction of EF compared to its reference value. Increasing EF has the opposite effect, delaying the formation of clouds and the triggering of deep convection. For higher values of EF, the growth of the PBL is very slow, clouds are further delayed, and no deep convection is triggered at all.

Situations in which drying the soil can facilitate convection-so-called dry advantage regimes-have been predicted by theoretical and modeling studies (Ek 
and Holtslag 2004; Stefanon et al. 2012; Gentine et al. 2013c). They are typical of either very arid environments (see the same study for the tropical semiarid case in section $5 \mathrm{~b}$ below) or of situations of low vertical stability like the present one, such as Fig. 5 of Gentine et al. (2013c). Note, however, that the cloud height is also reduced by a drying of the soil and, consequently, the total rainfall. Hence, there is a negative feedback of an increase of soil moisture on cloud formation and convection triggering but a positive one on rainfall. The behavior of PPM is substantially more complex than the theoretical frameworks cited above.

\section{Tropical semiarid case}

Our second test case is derived from conditions observed over Niamey in West Africa on 10 July 2006 during the AMMA campaign (Redelsperger et al. 2006). Lothon et al. (2011) and CA12 provide extensive descriptions of the prevailing meteorological conditions and observations. Briefly, a convective system was present on the test date and was associated with a buildup of shallow clouds until a tall cumulonimbus formed around 1630 LT (1530 UTC), but with little rain falling. The low-level monsoonal flow had developed, but few mesoscale convective systems occurred prior to $10 \mathrm{July}$, so overall rainfall had been light.

A combination of instruments deployed at the Mobile ARM facility, including radar and soundings, observed the vertical state of the atmosphere and surface fluxes on the test date. CA12 used these observations to implement an LES of deep convective triggering. The LES was run on a $100 \times 100 \mathrm{~km}^{2}$ domain with 500 -m horizontal resolution and a vertical resolution ranging from $50 \mathrm{~m}$ in the lower layers to $250 \mathrm{~m}$ aloft, using MesoNH (Lafore et al. 1998). The aridity of the soil at Niamey on the test date resulted in high surface sensible heat flux and low latent heat flux, while the monsoon flow induced large-scale cooling and moistening in the lowermost layers of the atmosphere.

\section{a. PPM integration}

The same data of CA12 are used here to force PPM. The integration is initiated at $0900 \mathrm{LT}$, after a convective boundary layer had already formed. From the initial profiles (not shown), we estimated an initial value for $z_{i}$ of $500 \mathrm{~m}$. The integration is interrupted at $2000 \mathrm{LT}$, at the onset of the nighttime stable boundary layer. CA12 introduced an ad hoc vertical velocity forcing in order to reproduce the effects of mesoscale surface-induced convergence and surface heterogeneities. This forcing was implemented as a time-dependent positive vertical velocity anomaly attaining a maximum of $1.5 \mathrm{~cm} \mathrm{~s}^{-1}$ between
1500 and $3000 \mathrm{~m}$ at $1200 \mathrm{LT}$ and gradually diminishing to zero at other levels and other times. The same vertical velocity forcing is applied in the PPM simulation.

As in the previous case, we show in Fig. 7 the lowerlayer temperature and humidity profiles at 1200 and 1800 LT. The PPM compares well to the LES profiles, except for a slightly colder PBL (around $-0.3 \mathrm{~K}$ ) at 12:00 LT. This is similar to the PBL cold bias noted in the summer midlatitude test case and likely arises from the lack of radiative heating effect of low clouds in PPM. The thickness of the dry inversion layer also appears underestimated. However, in contrast to the summer midlatitude case, the PBL at 1800 LT is neither too hot nor too humid: since the initial mass flux in this case is very low, underestimation of the downdraft mass flux has a negligible impact.

In Fig. 8 the diurnal evolution of PPM is depicted. This figure should be compared with Figs. 3 and 8 of CA12, showing, respectively, the radar reflectivity and the cloud heights obtained from the LES integration. Lidar/ radar measurements of cloud base and top (triangles and squares) as well as a satellite infrared radiometry estimate of cloud top (asterisks) are also included in Fig. 8. Shallow cumulus clouds are created in the late morning and do not grow much until deep convection triggering occurs later in the afternoon between 1430 and 1600 LT. In the LES integration of CA12, the shallow clouds also appear in the late morning, but they keep growing gradually to well above freezing level, until the abrupt growth in cloud top evident around 1630 LT. (Note the cloud top and base for this integration are represented by the thin dotted lines in Fig. 8.) PPM reflects more abrupt growth of clouds at $1430 \mathrm{LT}$, which is more similar to the available observations. A tendency for slower triggering by lower-resolution models was already noted by Khairoutdinov et al. (2009), with higher resolutions $(200 \mathrm{~m})$ producing a longer forced-fair weather convection regime but a more abrupt deep convective initiation. Hanley et al. (2014) also noted an improvement in the simulation of storms passing from 500- to 200-m resolution.

Little rain, less than $1 \mathrm{~mm} \mathrm{day}^{-1}$ for about $3 \mathrm{~h}$, is produced by PPM. This is in agreement with the observations: only one out of the 54 stations around Niamey recorded a small amount (about $15 \mathrm{~mm}$ ) of precipitation that day. The LES integration of CA12 also produced less than a millimeter of accumulated rainfall for the day. The top of the cloud in PPM reaches less than $7.5 \mathrm{~km}$, while observed and CRM-simulated cloud tops exceed $13 \mathrm{~km}$. As in the preceding case, the lack of a mechanical and thermodynamical lifting forcing from the converging density currents created by downdrafts likely contributes to this underestimation. In our 

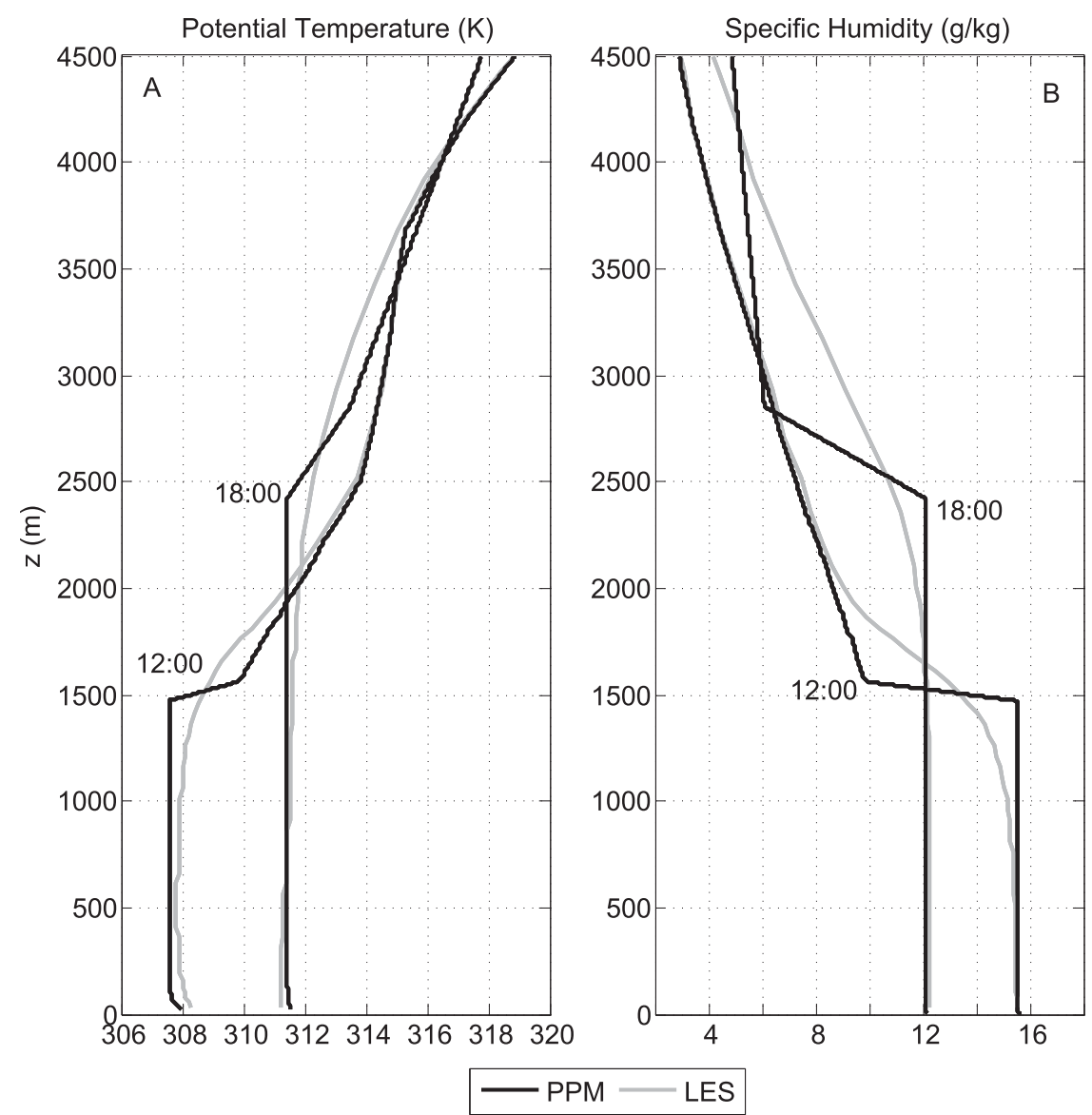

FIG. 7. (a) Potential temperature profiles (K) at 1200 and 1800 LT and (b) specific humidity profiles $\left(\mathrm{g} \mathrm{kg}^{-1}\right)$ at 1200 and 1800 LT. PPM is the black line and LES is the gray line.

parameterization we only account for the change in lateral entrainment induced by the cold pools. Note that the expansion of cold pools was observed in the area (CA12).

As in Fig. 4, we present the time evolution of virtual potential temperature for the 10 July 2006 case (Fig. 9). Around 1000 LT, forced clouds are first created. The most energetic updrafts became buoyant slightly before 1500 LT (the dashed line is below the top of the gray area), clouds become active, and deep convection is triggered. The virtual potential temperature and velocity profiles of the first active updraft-appearing at 1455 LT - are represented in Fig. 10. The $\theta_{v}$ profile of the environment (gray line in Fig. 10a) has a marked bend at around $2600 \mathrm{~m}$, above which the profile is particularly unstable. As soon as the most energetic parcels reach the LFC $(3000 \mathrm{~m})$, they become buoyant until above the freezing level at $5000 \mathrm{~m}$. The first updraft remains negatively buoyant above the dry inversion layer, but its kinetic energy is sufficient (see Fig. 10b) to reach the LFC. The updraft then becomes buoyant and overshoots the LNB up to slightly below $6000 \mathrm{~m}$. Precipitation starts at this point and the following updrafts rise progressively higher until reaching the maximum cloud height just below $7500 \mathrm{~m}$ around $1730 \mathrm{LT}$.

\section{b. Sensitivity study}

As in section $4 \mathrm{~b}$, we performed a sensitivity analysis for the tropical semiarid case for the same parameters in Table 1; see Table 2. Additionally, we have investigated the sensitivity to the value of the large-scale vertical velocity in the model simulation like in CA12. The sensitivities to $c_{\epsilon}, \alpha, l_{p}$, and $\Delta p_{\min }$ are all consistent with those seen above for the summer midlatitude case. The main difference is that the effect of the change of downdraft mass flux is smaller, because the overall mass flux-and precipitation-is small.

The sensitivity to EF has the same sign as in the summer midlatitude case, with an advance of the deep convection time with a reduction of $\mathrm{EF}$ and a delay with an increase. This again points to a dry surface advantage regime of deep convection (Gentine et al. 2013c). Preferential initiation of convection over dry soil 


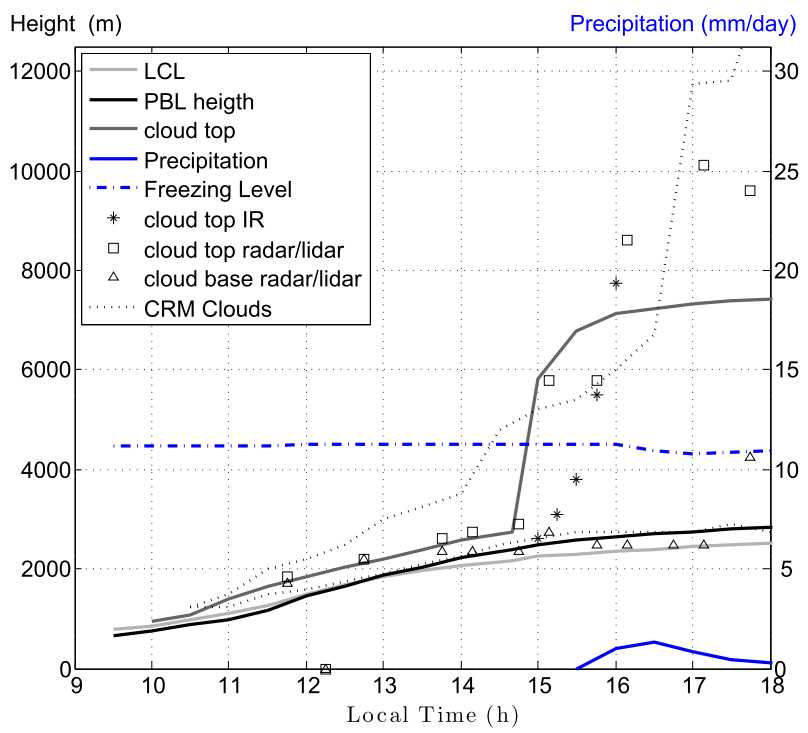

FIG. 8. Time evolution of the PBL height, LCL, cloud-top height, and precipitation for the tropical semiarid case. The triangles represent the cloud base as measured from radar/lidar. The asterisks and the squares are the cloud top measured by infrared satellite and radar/lidar, respectively. The cloud base and cloud top of the LES integration of CA12 are represented by the dotted lines.

patches has been documented over West Africa in the context of AMMA [see Taylor et al. (2012) and references therein]. This preference for dry conditions has been attributed to mesoscale circulations triggered by differential heating over soil moisture gradients, creating convergence on the dry side. The PPM provides support to the local process concept of Gentine et al. (2013c) and Ek and Holtslag (2004) that also favors convection over dry soil but without the intervention of the mesoscale.

Results of the sensitivity to changing the imposed vertical velocity profile are in general agreement with CA12. In particular, the triggering of deep convection is advanced by up to $1 \mathrm{~h}$ if the vertical velocity forcing is doubled, and delayed by a reduction, until there is no triggering of convection at all if this forcing is set to zero. In CA12 the sensitivity to the vertical velocity profile was found to be more pronounced.

\section{Summary and conclusions}

In this study, we have introduced a model, the probabilistic plume model (PPM), based on the framework of GA13a and GA13b, that unifies the representation of dry, shallow, and the transition to deep convection. PPM is based on an ensemble of entraining plumes, generated at the surface, that rise into and above the PBL. The surface sensible and latent heat fluxes

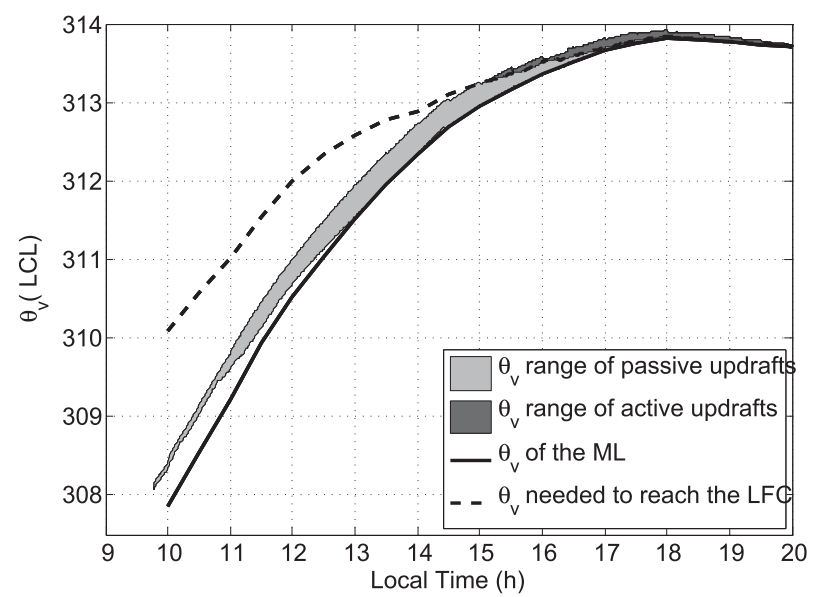

FIG. 9. As in Fig. 4, but for the tropical semiarid case.

define the probability density function of the plumes' temperature and humidity. The probabilistic plume approach ensures a tight coupling between the subcloudlayer vertical entrainment velocity and the mass flux closure: the entrainment velocity of the subcloud layer is defined as the average speed of the plumes reaching the top of the inversion capping the subcloud layer, while the mass flux at cloud base is determined by the most buoyant plumes [i.e., those that can reach their level of free convection (LFC)]. As soon as the parcels reach their LFC, clouds start growing, and when they become sufficiently thick, precipitation commences. When precipitation reaches the ground, reduction of updraft lateral entrainment, reflecting the organization of turbulence by downdrafts, stimulates further growth of the cloud from precipitating congestus to cumulonimbus.

PPM was forced with data corresponding to two case studies and compared with CRM and LES integrations. The two test cases examined correspond to summertime midlatitude conditions from the U.S. Southern Great Plains and semiarid tropical conditions at the beginning of the monsoon in West Africa. In both cases, PPM triggers shallow and deep convection at the appropriate times in the diurnal cycle, and precipitation has reasonable values. The growth of the cloud thickness is as sharp as in the observations even though no switch is imposed between shallow and deep convection. However, cloud height appears to be generally underestimated.

Two important differences of PPM compared to existing convection parameterizations warrant consideration. First, the same scheme applies to all conditions: clear sky, forced clouds, shallow cumuli, and deep cumuli. In particular, the transitions between 


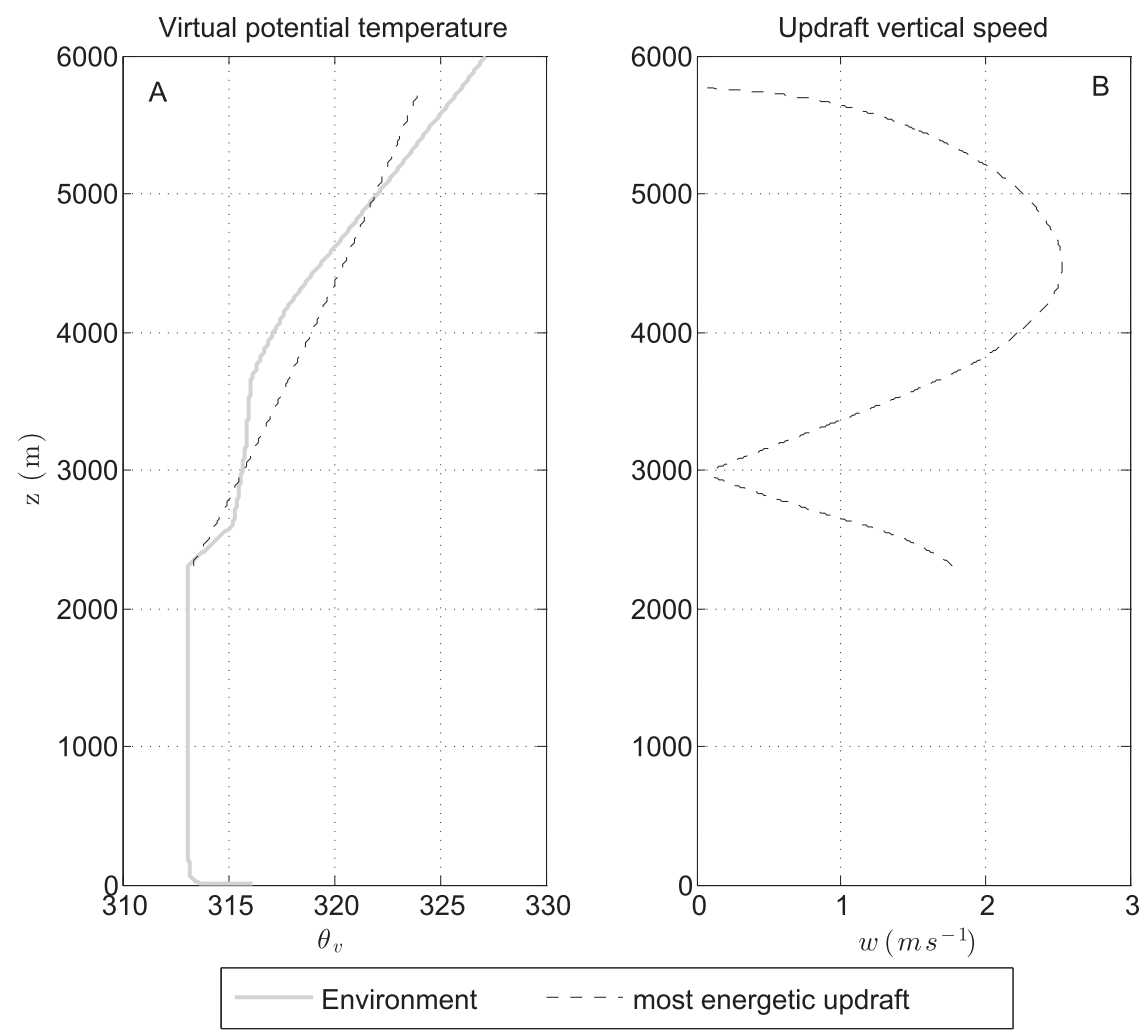

FIG. 10. As in Fig. 5, but for the tropical semiarid case. In this case the profile of buoyancy is not shown.

conditions are implicit rather than imposed a priori as in other convection parameterizations. The convection state is determined by the interplay among surface heat fluxes, boundary layer growth, and external environmental forcing. Second, the triggering of moist convection and cloud-base mass flux closure are based on the same plume statistics rather than independently prescribed. The variability of the surface forcing and the mass flux closure are hence coupled in PPM, through the boundary layer turbulence. Most current GCM convection parameterizations apply triggering criteria based on convective instability considerations, while

TABLE 2. Summary of the sensitivity integrations: tropical semiarid case.

\begin{tabular}{|c|c|c|c|c|c|}
\hline Brief description of integration & $\begin{array}{l}\text { Parameter } \\
\text { values }\end{array}$ & $\begin{array}{l}\text { Low cloud } \\
\text { time (LT) }\end{array}$ & $\begin{array}{l}\text { Deep cloud } \\
\text { time }(\mathrm{LT})\end{array}$ & $\begin{array}{l}\text { Max cloud } \\
\text { height }(\mathrm{m})\end{array}$ & $\begin{array}{c}\text { Accumulated } \\
\text { rainfall }\left(\mathrm{kg} \mathrm{m}^{-2}\right)\end{array}$ \\
\hline Reference & & 0955 & 1455 & 7414 & 0.09 \\
\hline \multirow[t]{2}{*}{ Lateral entrainment; reference $=1.0$} & $c_{\epsilon}=0.8$ & 0955 & 1428 & 7804 & 0.27 \\
\hline & $c_{\epsilon}=1.2$ & 0955 & 1525 & 6936 & 0 \\
\hline \multirow[t]{2}{*}{ Downdraft mass flux; reference $=0.2$} & $\alpha_{d}=0.5$ & 0955 & 1455 & 7109 & 0 \\
\hline & $\alpha_{d}=0.8$ & 0955 & 1455 & 7017 & 0 \\
\hline \multirow{2}{*}{$\begin{array}{l}\text { Autoconversion threshold; } \\
\text { reference }=1\left(\mathrm{~g} \mathrm{~kg}^{-1}\right)\end{array}$} & $l_{p}=0.5$ & 0955 & 1455 & 7115 & 0.07 \\
\hline & $l_{p}=2$ & 0955 & 1455 & 7642 & 0.04 \\
\hline $\begin{array}{l}\text { Min cloud height for precipitation; } \\
\text { reference }=150(\mathrm{hPa})\end{array}$ & $\Delta p_{\min }=50$ & 0955 & 1455 & 6890 & 0.56 \\
\hline \multirow{3}{*}{$\begin{array}{l}\text { Evaporative Fraction; reference }=0.09 \\
\quad(\% \text { of reference })\end{array}$} & $50 \%$ & 0951 & 1445 & 7433 & 0.07 \\
\hline & $150 \%$ & 1000 & 1530 & 7334 & 0.08 \\
\hline & $200 \%$ & 1000 & 1625 & 7121 & 0.03 \\
\hline \multirow{4}{*}{$\begin{array}{l}\text { Large scale vertical velocity; } \\
\quad \text { reference }=1.5\left(\mathrm{~cm} \mathrm{~s}^{-1}\right)\end{array}$} & 0 & 1000 & None & 270 & 0 \\
\hline & 1.0 & 1000 & 1550 & 7255 & 0.01 \\
\hline & 2.0 & 955 & 1430 & 7527 & 0.21 \\
\hline & 3.0 & 950 & 1355 & 7677 & 0.53 \\
\hline
\end{tabular}


some also include moisture convergence criteria (see Table 2 in GA04). On the other hand, relatively few models include in the convective stability criteria some consideration on the convective activity in the boundary layer (Kain and Frisch 1990; Jakob and Siebesma 2003).

Closures based on convective inhibition (CIN), like the one of Mapes (2000), also permit a coupling of the boundary layer dynamics and the cloud-base mass flux, and they do share some features with our formulation (Fletcher and Bretherton 2010). In PPM, however, the definition of CIN is generalized, since the inhibition of each updraft is defined and a probability assigned to it; a fraction of the ensemble of plumes can overcome inhibition at all times, leading to either shallow or deep convection. In most CIN-based closures, a single, bulk updraft is used to diagnose the inhibition: in the cases studied here, the CIN is generally negative and thus convection would not be triggered. Another advantage of the probabilistic approach is that it permits the straightforward treatment of the nonequilibrium state of diurnal convection over land. In CAPE-based closures, the relaxation toward equilibrium occurs over a prescribed time scale depending on different factors. By contrast, in PPM, a fraction of the PDF of updrafts is constantly removing any instability when convection is triggered there, as observed in domain-averaged CRMs (Muller and Held 2012).

As previously noted, lateral entrainment is reduced when the precipitation reaches the ground. Hohenegger and Bretherton (2011) introduced a similar dependence of the lateral entrainment rate to the precipitation intensity. Our argument for reducing entrainment is that the appearance of precipitation facilitates the transition from the cumulus congestus to the cumulonimbus stage through the organization of subcloud-layer turbulence by cold pools. As demonstrated in LES studies, density currents induce larger, less-entraining updrafts (Schlemmer and Hohenegger 2014). It is often hypothesized that the shallow convection and cumulus congestus stages precondition the environment for deep convection by the humidification of the upper troposphere via moisture detrainment (Guichard et al. 2004; Waite and Khouider 2010; Hirons et al. 2013). In PPM, at least in the two cases presented, the atmospheric column is already very close to the moist adiabatic profile early in the morning before the creation of congestus phase clouds, possibly reflecting prior moistening via shallow convection: the transition to deep convection occurs so rapidly that subdiurnal congestus moistening has negligible impact, which is consistent with recent analysis (Hohenegger and Stevens 2013). Indeed, for the summer midlatitude case, the transition to the stage of deep cumulus is too fast $(1-2 \mathrm{~h})$ to allow for the humidification process. In the tropical semiarid case, the phase of forced and active shallow convection is longer, but comparison of the environmental profiles before the first appearance of clouds and at the end of the shallow convective phase (not shown) indicates very little difference. However, exploration of more case studies is clearly warranted.

A missing element that could further increase the deepening and duration of deep convection is the explicit inclusion of a cold pool parameterization on the initial updraft velocity and moist static energy anomaly. Cold pools generate mechanical lift through the action of density currents at the edges of the cold pools (Grandpeix and Lafore 2010; Grandpeix et al. 2010; Schlemmer and Hohenegger 2014), especially during their collision. Another major effect of cold pools is the introduction of a positive moisture anomaly at the gust front, which facilitates the triggering of convection by increasing the moist static energy of the updrafts. These effects would modify the surface pdfs and lead to additional updraft moistening (Tompkins 2001; Schlemmer and Hohenegger 2014). The relative importance of these different processes remains the object of active research and still needs to be clarified, though some efforts have been taken to include these in convection parameterizations (Grandpeix and Lafore 2010; Hohenegger and Bretherton 2011; Rio et al. 2013). In our analysis, we opted for simplicity in maintaining the shape of the pdfs by restricting the effect of downdrafts to changes in plume geometry rather than mixed-layer thermodynamics. In subsequent work, a simple physically based representation of cold pools will be included in order to obtain a fully unified representation of dry, shallow, and deep convection. Another aspect of PPM configuration that may account for low cloud-top height is the deterministic lateral entrainment scheme. Stochastic entrainment models have shown the potential to correctly represent transport and the spread of plumes in the cumulus layer (Romps and Kuang 2010; Nie and Kuang 2012). Of course, implementation of such schemes in PPM would lead to a less tractable framework.

PPM is not meant to be a new parameterization of convection but rather a simplified process-oriented model. The simplification of the system to a small number of relevant equations, for which semianalytic solutions can be obtained, allows us to identify physical mechanisms that are difficult to infer from more complex numerical models. The sensitivity analyses for evaporative fraction and microphysics exemplify the power of the simplified approach adopted in PPM. We argue that approaches trading detailed physical realism for analytic tractability and insight (Brubaker and Entekhabi 1996) can be used to build intuition about the physical 
processes at play and to stimulate the development of diagnostics for interpreting full-fledged models.

Acknowledgments. This work was partly carried out under the Department of Energy Grant DE-FOA0000885 with Prof. Zhiming Kuang and the LEFE/ IMAGO project "Bulk-Deep." The visit of PG to Paris was funded by the Department of Geosciences of the Ecole Normale Superieure. The authors thank Maximilien Bolot, Jean-Pierre Chaboureau, Fleur Couvreux, Jean-Philippe Duvel, Francoise Guichard, Jean-Yves Grandpeix, Catherine Rio, Nicolas Rochetin, Steven Sherwood, and Adam Sobel for stimulating discussions.

\section{APPENDIX A}

\section{Precipitation Parameterization}

At all times, the liquid and ice water in the cumulus layer is given by the bulk updraft characteristics:

$$
q_{p}(z)=f_{u} \rho\left(q_{l}^{u}+q_{i}^{u}\right)
$$

$$
\left\{\begin{array}{l}
\epsilon_{p}=0 \\
\epsilon_{p}=0.99 \frac{\Delta p_{\min }-p}{\Delta p_{\max }-\Delta p_{\min }} \\
\epsilon_{p}=0.99
\end{array}\right.
$$

Summing up, the precipitation rate of production $\left(\mathrm{kg} \mathrm{m}^{-3} \mathrm{~s}^{-1}\right)$ at all levels $z$ will be

$$
P=\frac{1}{\delta t} \epsilon_{p} \frac{M_{u}}{w_{u}}\left(q_{l}^{u}+q_{i}^{u}-l_{c}\right) .
$$

Integrating the local production of precipitation from the top of the cloud to $z$ gives the precipitation flux at $z$. But the integral is carried out subtracting the local evaporation $E$ of raindrops. This is given by

$$
E=f_{p} \rho K_{e}(1-\mathrm{RH}) P^{1 / 2},
$$

where $K_{e}$ is an adjustable constant, set to $10^{-6}$ by Boville et al. (2006), RH is the relative humidity, and $f_{p}$ represents the fraction of rain falling outside of the cloud; it is taken equal to 0.5 in the cloud layer and 1 below the LCL. In conclusion, subtracting (A3) from (A2) and integrating from cloud top to the surface we get the precipitation.

The updraft will lose water owing to the precipitation; this will make it more buoyant because of the loss of water loading. In the definition of virtual potential where $f_{u}$ and $\rho$ are the fraction of updrafts and the density, both a function of height. The variables $q_{l}^{u}(z)$ and $q_{i}^{u}(z)$ are, respectively, the specific amounts of liquid and ice water in the updraft. We use the bulk updraft for reference. Using $M_{u}=f_{u} \rho w_{u}$ we can express it in terms of the mass flux:

$$
q_{p}=\frac{M_{u}}{w_{u}}\left(q_{l}^{u}+q_{i}^{u}\right) .
$$

All the cloud water that is in excess of a threshold $l_{c}$ is converted into precipitation via a precipitation efficiency $\epsilon_{p}$. Precipitation is composed of ice and liquid water in the same proportion as in the updrafts. Introducing an adjustable time scale $\delta t$, one obtains a rate of precipitation creation at all level $z ; \delta t$ is set to $15 \mathrm{~s}$. The threshold is set to $1 \mathrm{~g} \mathrm{~kg}^{-1}$ following Hohenegger and Bretherton (2011). The precipitation efficiency (Emanuel 1991) is a linear function of the cloud depth (in pressure). It is 0 below $\Delta p_{\text {min }}=150 \mathrm{hPa}$ of cloud depth, and then it increase linearly up to 0.99 above $\Delta p_{\text {max }}=500 \mathrm{hPa}$ :

$$
\begin{aligned}
& p_{\mathrm{LCL}}-p_{\text {top }}<\Delta p_{\text {min }} \\
& \Delta p_{\text {min }} \leq p_{\mathrm{LCL}}-p_{\text {top }} \leq \Delta p_{\text {max }} \\
& p_{\mathrm{LCL}}-p_{\text {top }}>\Delta p_{\text {max }} .
\end{aligned}
$$

temperature, we reduce the loading terms due to ice and liquid water:

$$
\theta_{v}^{u}=\theta_{u}\left[1+\epsilon q_{u}-\left(1-\epsilon_{p}\right)\left(q_{l}^{u}+q_{i}^{u}\right)\right]
$$

\section{APPENDIX B}

\section{PBL Entrainment Velocity and Balances}

The PBL height, temperature, and humidity are modified when the convective downdrafts penetrate the PBL. In GA13b, the PBL-height evolution is given by

$$
\rho \frac{d h}{d t}=\rho w_{e}-M_{u}^{\mathrm{active}}+\rho \bar{w},
$$

where $M_{u}^{\text {active }}$ is the mass flux of the convectively active plumes that leave the boundary layer and $\bar{w}$ is the largescale vertical velocity. The "dry" entrainment velocity $w_{e}$ is computed as the mean speed of the updrafts overshooting the boundary layer height $h$ : 


$$
\rho w_{e}=M_{u}(h)=\rho \int_{\theta_{v, h}^{\prime}}^{\infty} w_{u}(h) \operatorname{pdf}\left[\theta_{v}^{\prime}(0)\right] d \theta_{v}^{\prime}(0),
$$

where $\theta_{v, h}$ is the minimum surface buoyancy needed to reach $h$ and $\operatorname{pdf}\left[\theta_{v}(0)\right]$ is the surface probability density distribution of the virtual temperature.

In the case of deep convection, where penetrative downdrafts enter the mixed layer, the rate of growth of the mixed layer is

$$
\rho \frac{d h}{d t}=\rho w_{e}-M_{u}^{\text {active }}+M_{d}+\rho \bar{w}
$$

where we take into account the increase of boundary layer mass due to the contribution of the downdrafts.

The tendency of the conserved variables, $\phi=\left(\theta_{i l}, q_{\mathrm{tot}}\right) \approx$ $(\theta, q)$, in the mixed layer becomes

$$
\begin{aligned}
\rho h \frac{d \bar{\phi}}{d t}= & \overline{w^{\prime} \phi^{\prime}}(0)+\rho w_{e} \Delta \phi-M_{u}^{\text {active }}\left(\phi_{u}-\bar{\phi}\right) \\
& +M_{d}\left(\phi_{d}-\bar{\phi}\right)
\end{aligned}
$$

Here, we take for the value of $\phi_{d}$ the mean of the values of the downdraft temperature or humidity at the top and at the bottom of the subcloud layer, which corresponds to approximating their profiles as linear (see the discussion in section $3 \mathrm{~d}$ ).

\section{REFERENCES}

Arakawa, A., 2004: The cumulus parameterization problem: Past, present, and future. J. Climate, 17, 2493-2525, doi:10.1175/ 1520-0442(2004)017<2493:RATCPP > 2.0.CO;2.

Bechtold, P., J.-P. Chaboureau, A. C. M. Beljaars, A. K. Betts, M. Köhler, M. Miller, and J.-L. Redelsperger, 2004: The simulation of the diurnal cycle of convective precipitation over land in a global model. Quart. J. Roy. Meteor. Soc., 130, 31193137, doi:10.1256/qj.03.103.

—, N. Semane, P. Lopez, J.-P. Chaboureau, A. C. M. Beljaars, and N. Bormann, 2014: Representing equilibrium and nonequilibrium convection in large-scale models. J. Atmos. Sci., 71, 734-753, doi:10.1175/JAS-D-13-0163.1.

Betts, A. K., 1976: The thermodynamics transformation of the tropical subcloud layer by precipitation and downdrafts. J. Atmos. Sci., 33, 1008-1020, doi:10.1175/1520-0469(1976)033<1008: TTTOTT $>2.0 . \mathrm{CO} ; 2$.

—_, and M. F. Silva Dias, 1979: Unsaturated downdraft thermodynamics in cumulonimbus. J. Atmos. Sci., 36, 1061-1071.

— , and C. Jakob, 2002: Study of diurnal cycle of convective precipitation over Amazonia using a single column model. J. Geophys. Res., 107, 4732, doi:10.1029/2002JD002264.

Bogenschutz, P. A., S. K. Krueger, and M. F. Khairoutdinov, 2010: Assumed probability density functions for shallow and deep convection. J. Adv. Model. Earth Syst., 2 (4), doi:10.3894/ JAMES.2010.2.10.

Böing, S. J., H. J. J. Jonker, A. P. Siebesma, and W. W. Grabowski, 2012: Influence of the subcloud layer on the development of a deep convective ensemble. J. Atmos. Sci., 69, 2682-2698, doi:10.1175/JAS-D-11-0317.1.

Boville, B. A., P. J. Rasch, J. J. Hack, and J. R. McCaa, 2006: Representation of clouds and precipitation processes in the Community Atmosphere Model version 3 (CAM3). J. Climate, 19, 2184-2198, doi:10.1175/JCLI3749.1.

Bretherton, C. S., H. Grenier, and J. R. McCaa, 2004: A new parameterization for shallow cumulus convection and its application to marine subtropical cloud-topped boundary layers. Part I: Description and 1D results. Mon. Wea. Rev., 132, 864-882, doi:10.1175/1520-0493(2004)132<0864:ANPFSC>2.0.CO;2.

Brubaker, K. L., and D. Entekhabi, 1996: Analysis of feedback mechanisms in land-atmosphere interaction. Water Resour. Res., 32, 1343-1357, doi:10.1029/96WR00005.

Bryan, G. H., and M. J. Fritsch, 2004: A reevaluation of ice-liquid water potential temperature. Mon. Wea. Rev., 132, 2421-2431, doi:10.1175/1520-0493(2004)132<2421: AROIWP $>2.0 . C O ; 2$.

Chaboureau, J.-P., F. Guichard, J.-L. Redelsperger, and J.-P. Lafore, 2004: The role of stability and moisture in the diurnal cycle of convection over land. Quart. J. Roy. Meteor. Soc., 130, 31053117, doi:10.1256/qj.03.132.

Couvreux, F., C. Rio, F. Guichard, M. Lothon, G. Canut, D. Bouniol, and A. Gounou, 2012: Initiation of daytime local convection in a semi-arid region analysed with high-resolution simulations and AMMA observations. Quart. J. Roy. Meteor. Soc., 138, 56-71, doi:10.1002/qj.903.

Crago, R. D., 1996a: Comparison of the evaporative fraction and the Priestley-Taylor $\alpha$ for parameterizing daytime evaporation. Water Resour. Res., 32, 1403-1409, doi:10.1029/96WR00269.

- 1996b: Conservation and variability of the evaporative fraction during the daytime. J. Hydrol., 180, 173-194, doi:10.1016/ 0022-1694(95)02903-6.

Dai, A., 2006: Precipitation characteristics in eighteen coupled climate models. J. Climate, 19, 4605-4630, doi:10.1175/ JCLI3884.1.

— piction in the Community Climate System Model. J. Climate, 17, 930-951, doi:10.1175/1520-0442(2004)017<0930: TDCAID $>2.0 . \mathrm{CO} ; 2$.

Del Genio, A. D., and J. Wu, 2010: The role of entrainment in the diurnal cycle of continental convection. J. Climate, 23, 27222738, doi:10.1175/2009JCLI3340.1.

Derbyshire, S., I. Beau, P. Bechtold, J.-Y. Grandpeix, J.-M. Piriou, J.-L. Redelsperger, and P. M. M. Soares, 2004: Sensitivity of moist convection to environmental humidity. Quart. J. Roy. Meteor. Soc., 130, 3055-3079, doi:10.1256/qj.03.130.

De Rooy, W. C., and A. P. Siebesma, 2010: Analytical expressions for entrainment and detrainment in cumulus convection. Quart. J. Roy. Meteor. Soc., 136, 1216-1227, doi:10.1002/qj.640.

_ and Coauthors, 2013: Entrainment and detrainment in cumulus convection: An overview. Quart. J. Roy. Meteor. Soc., 139, 1-19, doi:10.1002/qj.1959.

Dufresne, J.-L., and S. Bony, 2008: An assessment of the primary sources of spread of global warming estimates from coupled atmosphere-ocean models. J. Climate, 21, 5135-5144, doi:10.1175/2008JCLI2239.1.

Ek, M. B., and A. M. Holtslag, 2004: Influence of soil moisture on boundary layer cloud development. J. Hydrometeor., 5, 86-99, doi:10.1175/1525-7541(2004)005<0086:IOSMOB>2.0.CO;2.

Emanuel, K., 1991: A scheme for representing cumulus convection in large-scale models. J. Atmos. Sci., 48, 2313-2335, doi:10.1175/ 1520-0469(1991)048<2313:ASFRCC >2.0.CO;2. 
Emori, S., 1998: The interaction of cumulus convection with soil moisture distribution: An idealized simulation. J. Geophys. Res., 103, 8873-8884, doi:10.1029/98JD00426.

Fletcher, J. K., and C. S. Bretherton, 2010: Evaluating boundary layer-based mass flux closures using cloud-resolving model simulations of deep convection. J. Atmos. Sci., 67, 2212-2225, doi:10.1175/2010JAS3328.1.

Gentine, P., D. Entekhabi, A. Chehbouni, G. Boulet, and B. Duchemin, 2007: Analysis of evaporative fraction diurnal behaviour. Agric. For. Meteor., 143 (1-2), 13-29, doi:10.1016/ j.agrformet.2006.11.002.

— _ _ and J. Polcher, 2011: The diurnal behavior of evaporative fraction in the soil-vegetation-atmospheric boundary layer continuum. J. Hydrometeor., 12, 1530-1546, doi:10.1175/ 2011JHM1261.1.

—, A. K. Betts, B. R. Lintner, K. L. Findell, C. C. van Heerwaarden, A. Tzella, and F. D'Andrea, 2013a: A probabilistic bulk model of coupled mixed layer and convection. Part I: Clear-sky case. J. Atmos. Sci., 70,1543-1556, doi:10.1175/ JAS-D-12-0145.1.

,,,,----- , and F. D'Andrea, 2013b: A probabilistic bulk model of coupled mixed layer and convection. Part II: Shallow convection case. J. Atmos. Sci., 70, 15571576, doi:10.1175/JAS-D-12-0146.1.

—, A. A. M. Holtslag, F. D'Andrea, and M. B. Ek, 2013c: Surface and atmospheric controls on the onset of moist convection over land. J. Hydrometeor., 14, 1443-1462, doi:10.1175/ JHM-D-12-0137.1.

Golaz, J.-C., V. E. Larson, and W. R. Cotton, 2002: A PDF-based model for boundary layer clouds. Part I: Method and model description. J. Atmos. Sci., 59, 3540-3551, doi:10.1175/ 1520-0469(2002)059<3540:APBMFB > 2.0.CO;2.

Grabowski, W. W., and Coauthors, 2006: Daytime convective development over land: A model intercomparison based on LBA observations. Quart. J. Roy. Meteor. Soc., 132, 317-344, doi:10.1256/qj.04.147.

Grandpeix, J.-Y., and J.-P. Lafore, 2010: A density current parameterization coupled with Emanuel's convection scheme. Part I: The models. J. Atmos. Sci., 67, 881-897, doi:10.1175/ 2009JAS3044.1.

,$- \ldots$, and F. Cheruy, 2010: A density current parameterization coupled with Emanuel's convection scheme. Part II: 1D simulations. J. Atmos. Sci., 67, 898-922, doi:10.1175/ 2009JAS3045.1.

Gregory, D., 2001: Estimation of entrainment rate in simple models of convective clouds. Quart. J. Roy. Meteor. Soc., 127, 53-72, doi:10.1002/qj.49712757104.

Guichard, F., and Coauthors, 2004: Modelling the diurnal cycle of deep precipitating convection over land with cloud-resolving models and single-column models. Quart. J. Roy. Meteor. Soc., 130, 3139-3172, doi:10.1256/qj.03.145.

Hanley, K. E., R. S. Plant, T. H. M. Stein, R. J. Hogan, J. C. Nicol, H. W. Lean, C. Halliwell, and P. A. Clark, 2014: Mixing-length controls on high-resolution simulations of convective storms. Quart. J. Roy. Meteor. Soc., doi:10.1002/qj.2356, in press.

Hirons, L. C., P. Inness, F. Vitart, and P. Bechtold, 2013: Understanding advances in the simulation of intraseasonal variability in the ECMWF model. Part II: The application of process-based diagnostics. Quart. J. Roy. Meteor. Soc., 139, 1427-1444, doi:10.1002/qj.2059.

Hohenegger, C., and C. S. Bretherton, 2011: Simulating deep convection with a shallow convection scheme. Atmos. Chem. Phys., 11, 10389-10 406, doi:10.5194/acp-11-10389-2011.
— and B. Stevens, 2013: Preconditioning deep convection with cumulus congestus. J. Atmos. Sci., 70, 448-464, doi:10.1175/ JAS-D-12-089.1.

Holloway, C. E., and J. D. Neelin, 2009: Moisture vertical structure, column water vapor, and tropical deep convection. J. Atmos. Sci., 66, 1665-1683, doi:10.1175/2008JAS2806.1.

Houze, R. A., Jr., and A. K. Betts, 1981: Convection in GATE. Rev. Geophys. Space Phys., 19, 541-576.

Jakob, C., and A. P. Siebesma, 2003: A new subcloud model for mass-flux convection schemes: Influence on triggering, updraft properties, and model climate. Mon. Wea. Rev., 131, 2765-2778, doi:10.1175/1520-0493(2003)131<2765:ANSMFM>2.0.CO;2.

Johnson, R. H., 1981: Large-scale effects of deep convection on the GATE tropical boundary layer. J. Atmos. Sci., 38, 2399-2413, doi:10.1175/1520-0469(1981)038<2399: LSEODC $>2.0 . \mathrm{CO} ; 2$.

Johnson, R. J., and R. A. Houze, 1987: Precipitating cloud systems of the Asian monsoon. Monsoon Meteorology, Chang, C.-P. and T. N. Krishnamurti, Eds., 298-353.

Kain, J. S., and J. M. Frisch, 1990: A one dimensional entraining/ detraining plume model and its applications to convective parameterization. J. Atmos. Sci., 47, 2784-2802, doi:10.1175/ 1520-0469(1990)047<2784:AODEPM>2.0.CO;2.

Khairoutdinov, M. F., and D. A. Randall, 2006: High-resolution simulation of shallow-to-deep convection transition over land. J. Atmos. Sci., 63, 3421-3436, doi:10.1175/JAS3810.1.

, S. K. Krueger, C.-H. Moeng, P. A. Bogenschutz, and D. A. Randall, 2009: Large-eddy simulation of maritime deep tropical convection. J. Adv. Model. Earth Syst., 1 (4), doi:10.3894/ JAMES.2009.1.15.

Kuang, Z., and C. S. Bretherton, 2006: A mass-flux scheme view of a high-resolution simulation of a transition from shallow to deep cumulus convection. J. Atmos. Sci., 63, 1895-1909, doi:10.1175/ JAS3723.1.

Lafore, J.-P., and Coauthors, 1998: The Meso-NH Atmospheric Simulation System. Part I: Adiabatic formulation and control simulations. Ann. Geophys., 109, 90-109, doi:10.1007/ s00585-997-0090-6.

Lappen, C.-L., and D. A. Randall, 2001a: Toward a unified parameterization of the boundary layer and moist convection. Part I: A new type of mass-flux model. J. Atmos. Sci., 58, 2021-2036, doi:10.1175/1520-0469(2001)058<2021:TAUPOT>2.0.CO;2. , and $\longrightarrow, 2001 \mathrm{~b}$ : Toward a unified parameterization of the boundary layer and moist convection. Part II: Lateral mass exchanges and subplume-scale fluxes. J. Atmos. Sci., 58, 2037-2051, doi:10.1175/1520-0469(2001)058<2037:TAUPOT>2.0.CO;2.

— and —, 2001c: Toward a unified parameterization of the boundary layer and moist convection. Part III: Simulations of clear and cloudy convection. J. Atmos. Sci., 58, 2052-2072, doi:10.1175/1520-0469(2001)058<2052:TAUPOT>2.0.CO;2.

Lintner, B. R., G. Bellon, A. H. Sobel, D. Kim, and J. D. Neelin, 2012: Implementation of the Quasi-equilibrium Tropical Circulation Model 2 (QTCM2): Global simulations and convection sensitivity to free tropospheric moisture. J. Adv. Model. Earth Syst., 4, M12002, doi:10.1029/2012MS000174.

Lothon, M., B. Campistron, M. Chong, F. Couvreux, F. Guichard, C. Rio, and E. Williams, 2011: Life cycle of a mesoscale circular gust front observed by a C-band Doppler radar in West Africa. Mon. Wea. Rev., 139, 1370-1388, doi:10.1175/2010MWR3480.1.

Mapes, B. M., 2000: Convective inhibition, subgrid-scale triggering energy, and stratiform instability in a toy tropical wave model. J. Atmos. Sci., 57, 1515-1535, doi:10.1175/ 1520-0469(2000)057<1515:CISSTE > 2.0.CO;2. 
— tion to escape the entrainment dilemma. J. Adv. Model. Earth Syst., 3, M06004, doi:10.1029/2011MS000042.

Mercado, L. M., J. Lloyd, A. J. Dolman, S. Sitch, M. Office, and H. Centre, 2009: Modelling basin-wide variations in Amazon forest productivity -Part 1: Model calibration, evaluation and upscaling functions for canopy photosynthesis. Biogeosciences, 6, 1247-1272, doi:10.5194/bg-6-1247-2009.

Muller, C. J., and I. M. Held, 2012: Detailed investigation of the self-aggregation of convection in cloud-resolving simulations. J. Atmos. Sci., 69, 2551-2565, doi:10.1175/JAS-D-11-0257.1.

Neggers, R. A. J., A. P. Siebesma, G. Lenderink, and A. M. Holtslag, 2004: An evaluation of mass flux closures for diurnal cycles of shallow cumulus. Mon. Wea. Rev., 132, 2525-2538, doi:10.1175/MWR2776.1.

— M. Köhler, and A. C. M. Beljaars, 2009: A dual mass flux framework for boundary layer convection. Part I: Transport. J. Atmos. Sci., 66, 1465-1487, doi:10.1175/2008JAS2635.1.

Nesbitt, S. W., and E. J. Zipser, 2003: The diurnal cycle of rainfall and convective intensity according to three years of TRMM measurements. J. Climate, 16, 1456-1475, doi:10.1175/ 1520-0442-16.10.1456.

Nie, J., and Z. Kuang, 2012: Beyond bulk entrainment and detrainment rates: A new framework for diagnosing mixing in cumulus convection. Geophys. Res. Lett., 39, L21803, doi:10.1029/ 2012GL053992.

Nikulin, G., and Coauthors, 2012: Precipitation climatology in an ensemble of CORDEX-Africa regional climate simulations. J. Climate, 25, 6057-6078, doi:10.1175/JCLI-D-11-00375.1.

Qian, L., G. S. Young, and W. M. Frank, 1998: A convective wake parameterization scheme for use in general circulation models. Mon. Wea. Rev., 126, 456-469, doi:10.1175/ 1520-0493(1998)126<0456:ACWPSF > 2.0.CO;2.

Redelsperger, J.-L., C. D. Thorncroft, A. Diedhiou, T. Lebel, D. J. Parker, and J. Polcher, 2006: African Monsoon Multidisciplinary Analysis: An international research project and field campaign. Bull. Amer. Meteor. Soc., 87, 1739-1746, doi:10.1175/ BAMS-87-12-1739.

Rio, C., F. Hourdin, F. Couvreux, and A. Jam, 2010: Resolved versus parametrized boundary-layer plumes. Part II: Continuous formulations of mixing rates for mass-flux schemes. Bound.-Layer Meteor., 135, 469-483, doi:10.1007/s10546-010-9478-z.

, and Coauthors, 2013: Control of deep convection by subcloud lifting processes: The ALP closure in the LMDZ5B general circulation model. Climate Dyn., 40 (9-10), 2271-2292, doi:10.1007/s00382-012-1506-x.

Romps, D. M., 2010: A direct measure of entrainment. J. Atmos. Sci., 67, 1908-1927, doi:10.1175/2010JAS3371.1.

_- and Z. Kuang, 2010: Nature versus nurture in shallow convection. J. Atmos. Sci., 67, 1655-1666, doi:10.1175/ 2009JAS3307.1.

Sahany, S., J. D. Neelin, K. Hales, and R. B. Neale, 2012: Temperature-moisture dependence of the deep convective transition as a constraint on entrainment in climate models. J. Atmos. Sci., 69, 1340-1358, doi:10.1175/JAS-D-11-0164.1.

Schlemmer, L., and C. Hohenegger, 2014: The formation of wider and deeper clouds through cold-pool dynamics. J. Climate, 71, 2842-2858, doi:10.1175/JAS-D-13-0170.1.

Sherwood, S. C., S. Bony, and J.-L. Dufresne, 2014: Spread in model climate sensitivity traced to atmospheric convective mixing. Nature, 505, 37-42, doi:10.1038/nature12829.

Siebesma, A. P., and Coauthors, 2003: A large eddy simulation intercomparison study of shallow cumulus convection. J. Atmos.
Sci., 60, 1201-1219, doi:10.1175/1520-0469(2003)60<1201: ALESIS $>2.0 . \mathrm{CO} ; 2$.

— , and Coauthors, 2004: Cloud representation in generalcirculation models over the northern Pacific Ocean: A EUROCS intercomparison study. Quart. J. Roy. Meteor. Soc., 130, 3245-3267, doi:10.1256/qj.03.146.

— P. M. M. Soares, and J. Teixeira, 2007: A combined eddydiffusivity mass-flux approach for the convective boundary layer. J. Atmos. Sci., 64, 1230-1248, doi:10.1175/JAS3888.1.

Simpson, J., and V. Wiggert, 1969: Models of precipitating cumulus towers. Mon. Wea. Rev., 97, 471-489, doi:10.1175/ 1520-0493(1969)097<0471:MOPCT>2.3.CO;2.

Stefanon, M., P. Drobinski, F. D'Andrea, and N. D. NobletDucoudré, 2012: Effects of interactive vegetation phenology on the 2003 summer heat waves. J. Geophys. Res., 117, D24103, doi:10.1029/2012JD018187.

Stirling, A. J., and R. A. Stratton, 2012: Entrainment processes in the diurnal cycle of deep convection over land. Quart. J. Roy. Meteor. Soc., 138, 1135-1149, doi:10.1002/qj.1868.

Stull, R. B., 1985: A fair-weather cumulus cloud classification scheme for mixed-layer studies. J. Climate Appl. Meteor., 24, 49-56, doi:10.1175/1520-0450(1985)024<0049:AFWCCC>2.0.CO;2.

Sullivan, P. P., and E. G. Patton, 2011: The effect of mesh resolution on convective boundary layer statistics and structures generated by large-eddy simulation. J. Atmos. Sci., 68, 23952415, doi:10.1175/JAS-D-10-05010.1.

Sušelj, K., J. Teixeira, and D. Chung, 2013: A unified model for moist convective boundary layers based on a stochastic eddydiffusivity/mass-flux parameterization. J. Atmos. Sci., 70, 1929-1953, doi:10.1175/JAS-D-12-0106.1.

Takemi, T., and T. Satomura, 2000: Numerical experiments on the mechanisms for the development and maintenance of long-lived squall lines in dry environments. J. Atmos. Sci., 57, 1718-1740, doi:10.1175/1520-0469(2000)057<1718:NEOTMF > 2.0.CO;2.

Taylor, C. M., R. A. M. de Jeu, F. Guichard, P. P. Harris, and W. A. Dorigo, 2012: Afternoon rain more likely over drier soils. Nature, 489, 423-426, doi:10.1038/nature11377.

Tiedtke, M., 1989: A comprehensive mass flux scheme for cumulus parameterization in large scale models. Mon. Wea. Rev., 117, 1779-1800, doi:10.1175/1520-0493(1989)117<1779: ACMFSF $>2.0 . \mathrm{CO} ; 2$.

Tompkins, A. M., 2001: Organization of tropical convection in low vertical wind shears: The role of water vapor. J. Atmos. Sci., 58, 529-545, doi:10.1175/1520-0469(2001)058<0529: OOTCIL $>2.0 . \mathrm{CO} ; 2$.

Waite, M. L., and B. Khouider, 2010: The deepening of tropical convection by congestus preconditioning. J. Atmos. Sci., 67, 2601-2615, doi:10.1175/2010JAS3357.1.

Weisman, M. L., and R. Rotunno, 2004: “A theory for strong longlived squall lines” revisited. J. Atmos. Sci., 61, 361-382, doi:10.1175/ 1520-0469(2004)061<0361:ATFSLS > 2.0.CO;2.

Wilde, N. P., R. B. Stull, and E. W. Eloranta, 1985: The LCL zone and cumulus onset. J. Climate Appl. Meteor., 24, 640-657, doi:10.1175/ 1520-0450(1985)024<0640:TLZACO > 2.0.CO;2.

Willett, M. R., P. Bechtold, D. L. Williamson, J. Petch, and S. F. Milton, 2008: Modelling suppressed and active convection: Comparisons between three global atmospheric models. Quart. J. Roy. Meteor. Soc., 134, 1881-1896, doi:10.1002/ qj.317.

Xu, K.-M., and D. A. Randall, 2001: Updraft and downdraft statistics of simulated tropical and midlatitude cumulus convection. J. Atmos. Sci., 58, 1630-1649, doi:10.1175/ 1520-0469(2001)058<1630:UADSOS>2.0.CO;2. 
Yang, G.-Y., and J. Slingo, 2001: The diurnal cycle in the tropics. Mon. Wea. Rev., 129, 784-801, doi:10.1175/1520-0493(2001)129<0784: TDCITT $>2.0 . \mathrm{CO} ; 2$.

Zhang, Y., and S. A. Klein, 2010: Mechanisms affecting the transition from shallow to deep convection over land: Inferences from observations of the diurnal cycle collected at the ARM Southern Great Plains site. J. Atmos. Sci., 67, 2943-2959, doi:10.1175/2010JAS3366.1.

$\longrightarrow$, and - 2013: Factors controlling the vertical extent of fairweather shallow cumulus clouds over land: Investigation of diurnal-cycle observations collected at the ARM Southern Great Plains site. J. Atmos. Sci., 70, 1297-1315, doi:10.1175/ JAS-D-12-0131.1.

Zipser, E. J., 1977: Mesoscale and convective scale downdrafts as distinct components of squall line structure. Mon. Wea. Rev., 105, 1568-1589, doi:10.1175/1520-0493(1977)105<1568: MACDAD $>2.0 . C O ; 2$.

Zuidema, P., and Coauthors, 2012: On trade wind cumulus cold pools. J. Atmos. Sci., 69, 258-280, doi:10.1175/ JAS-D-11-0143.1. 